\title{
Canadian and Alaskan wildfire smoke particle properties, their evolution, and controlling factors, from satellite observations
}

\author{
Katherine T. Junghenn Noyes ${ }^{1,2}$, Ralph A. Kahn ${ }^{3}$, James A. Limbacher ${ }^{3,4}$, Zhanqing Li $^{1,5}$ \\ ${ }^{1}$ Department of Atmospheric and Oceanic Science, University of Maryland, College Park, MD 20742, USA \\ $5 \quad{ }^{2}$ Universities Space Research Association, NASA Postdoctoral Program, Columbia, MD 21046, USA \\ ${ }^{3}$ Earth Science Division, NASA Goddard Space Flight Center, Greenbelt, MD 20771, USA \\ ${ }^{4}$ Department of Meteorology and Atmospheric Science, the Pennsylvania State University, State College, PA 168026, USA \\ ${ }^{5}$ Earth System Science Interdisciplinary Center, College Park, MD 20740, USA
}

Correspondence to: Katherine T. Junghenn Noyes (katherine.t.junghenn@nasa.gov)

10 Abstract. The optical and chemical properties of biomass burning (BB) smoke particles greatly affect the impact wildfires have on climate and air quality. Previous work has demonstrated some links between smoke properties and factors such as fuel type and meteorology. However, the factors controlling BB particle speciation at emission are not adequately understood, nor are those driving particle aging during atmospheric transport. As such, modeling wildfire smoke impacts on climate and air quality remains challenging. The potential to provide robust, statistical characterizations of BB particles

15 based on ecosystem type and ambient environmental conditions with remote sensing data is investigated here. Space-based Multi-angle Imaging Spectrometer (MISR) observations, combined with the MISR Research Aerosol (RA) algorithm and the MISR Interactive Explorer (MINX) tool, are used to retrieve smoke plume aerosol optical depth (AOD), and to provide constraints on plume vertical extent, smoke age, and particle size, shape, and light-absorption properties, and absorption spectral dependence. These tools are applied to numerous wildfire plumes in Canada and Alaska, across a range of conditions, to create a regional inventory of BB particle-type temporal and spatial distribution. We then statistically compare these results with satellite measurements of fire radiative power (FRP) and land cover characteristics, as well as short-term climate, meteorological, and drought information from MERRA-2 reanalysis and the North American Drought Monitor. We find statistically significant differences in the retrieved smoke properties based on land cover type, with fires in forests producing the thickest plumes containing the largest, brightest particles, and fires in savannas and grasslands exhibiting the opposite. Additionally, the inferred dominant aging mechanisms and the timescales over which they occur vary systematically between land types. This work demonstrates the potential of remote sensing to constrain BB particle properties and the mechanisms governing their evolution over entire ecosystems. It also begins to realize this potential, as a means of improving regional and global climate and air quality modeling in a rapidly changing world. 


\section{Introduction}

Wildfires can be significant emitters of trace gases and airborne particles, with the potential to meaningfully impact regional climate conditions as well as short-term local and regional air quality. Smoke emissions alter atmospheric composition by changing the concentration of gases and aerosols across time and space, in turn affecting the surrounding thermal, dynamical, and hydrological conditions. The precise impacts of wildfire emissions depend on a combination of the ambient meteorological and chemical conditions and, importantly, the composition of the smoke. Although $\mathrm{CO}_{2}$ and water vapor tend to dominate emissions, wildfires are a rich and complex mixture of many gas and aerosol constituents - most notably the greenhouse gases methane $\left(\mathrm{CH}_{4}\right)$ and nitrous oxide $\left(\mathrm{N}_{2} \mathrm{O}\right)$, a suite of volatile and semi-volatile organics, lightscattering aerosols and weakly absorbing soil or dust particles, and the light-absorbing aerosols black carbon (BC) and brown carbon $(\mathrm{BrC})$. Globally, wildfires are the most significant source of light-absorbing airborne particles [Bond et al.,

40 2013; Feng et al., 2013]. In addition to exhibiting distinct chemical properties, BC and BrC are optically unique in that BC is highly absorbing across all visible wavelengths, whereas $\mathrm{BrC}$ is less absorbing overall and displays enhanced lightabsorption at shorter wavelengths [Kirchstetter et al., 2004; Samset et al., 2018]. In the atmospheric chemistry community, the term "BC" is used to refer specifically to the refractory black carbon component (mid-visible SSA 0.4) that is usually internally mixed within aerosols, derived from in situ light-absorption measurements. In contrast, the remote sensing community often uses this term to describe the aerosol types (i.e., entire particles) that exhibit relatively strong (SSA $>\sim 0.7$ ), spectrally flat light-absorption. To avoid confusion, we henceforth refer to these particles as Black Smoke (BIS) and Brown Smoke (BrS), as these terms appropriately describe the spectral dependence of the retrieved SSA without directly connecting to specific chemical constituents. These light-absorbing particles can affect the local radiative budget by warming the ambient air layer and shading the surface, which in turn impacts atmospheric stability and may leading to changes in cloud

50 distribution and the water cycle [Albrecht, 1989; Kaufman and Fraser, 1997; Koch and Del Genio, 2010]. Smoke aerosols also often contribute towards poor air quality regionally, as particulate matter is dangerous to respiratory health, and the lofting of smoke plumes through plume-rise processes can lead to long-range horizontal transport, so that areas far downwind are also affected. Such plume-rise processes may also lead to smoke aerosols escaping the planetary boundary layer (PBL) and entering the free troposphere (FT), where they can stay aloft for several days or more [Damoah et al., 2004;

55 Taubman et al., 2004; Vant-Hull et al., 2005; Colarco et al., 2004; Kahn et al., 2008; Liu et al., 2014]. As such, they have the potential to further impact cloud formation and lifetime by serving as cloud condensation nuclei $(\mathrm{CCN})$ and possibly increasing cloud albedo via the Twomey effect, or, conversely, contributing to droplet warming and evaporation via the semi-direct effect [Kaufman and Fraser, 1997; Koch and Del Genio, 2010; Warner and Twomey, 1967; Hobbs and Radke, 1969; Hansen et al., 1997]. The resulting changes in cloud reflectivity and lifetime may then significantly alter climate 60 forcing.

Differences in the optical and physical properties of smoke particles indicate that the impacts of wildfires can vary widely. However, the conditions that mediate these differences at the point of emission are not well understood. Wildfires 
display a range of fire behavior and smoke characteristics that depend on factors such as vegetation type and fuel structure, terrain characteristics, as well as climate and weather patterns; together they influence, among other things, the relative degree of flaming or smoldering combustion at the source. Differences in fire regimes and environmental conditions are at least partially linked with differences in smoke particle properties, with evidence suggesting systematic differences in particle size distribution, particle light-absorption, and the spectral dependence of absorption [Dubovik et al., 2002; Chen et al., 2008; Eck et al., 2003; Shi et al., 2019; O’Neill et al., 2002]. For example, studies have suggested a connection between fire regime and particle size at the point of emission, with smoldering fires (lower combustion efficiency, or CE) generating

70 larger particles than flaming fires (higher CE) under many conditions [Reid and Hobbs, 1998; Reid et al., 2005]. These fire regimes have also been linked to smoke particle type - although $\mathrm{BC}$ is often the dominant absorbing aerosol component in biomass burning (BB) smoke, smoldering fires tend to produce higher fractions of $\mathrm{BrC}$ than flaming ones [Chakrabarty et al., 2010, 2016; Petrenko et al., 2012]. Compared to smoldering fires, flaming fires also emit less carbon monoxide (CO), volatile gases, and smoke per unit of fuel consumed [Urbanski, 2013; Wiggins et al., 2021]. Both smoldering and flaming regimes occur near-simultaneously in many fires; however, smoldering conditions are more common and may even dominate where fuel is coarse and moist, such as in forests, where the fire can penetrate the organic soil layer. In contrast, flaming conditions dominate over smoldering in regions of fine, grassy fuel that dry out quickly and can produce hightemperature combustion, such as savannas and grasslands [Ottmar, 2001; Urbanski, 2013; Gonzalez-Alonso et al., 2019; van der Werf et al., 2010]. These different vegetation types also emit different trace gases when burned, which in turn may

80 further impact particle chemistry both near-source and downwind [Akagi et al., 2011; van der Werf et al., 2010].

The microphysical properties and mixing state of smoke particles can change dramatically even a short distance away from the source, as aerosols interact with their environment through a variety of complex aging processes. For example, particles may increasingly undergo oxidation as they mix with background air, trace gases and sunlight, leading to both chemical and structural changes. Particles can also hydrate through the uptake of water vapor, leading to increases in

85 size and light scattering. As smoke cools away from the flame front, semi-volatile gases (known as volatile organic compounds, or VOCs) can condense onto existing emitted particles, creating organic or inorganic coatings that result in increased particle size and alter particle scattering as well as CCN efficiency, especially in the case of BIS (which is hydrophobic in its pure form) [Reid et al., 2005; Zhou et al., 2017; Yokelson et al., 2009; Akagi et al., 2012; Hennigan et al., 2012; Ahern et al., 2019; Dalirian et al., 2018]. VOCs can also spontaneously condense into new, very small particles in a

90 process known as secondary organic aerosol (SOA) formation, which results in a higher plume particle number concentration and a smaller average particle diameter across the plume [Akagi et al., 2012; Wang et al., 2013]. It is important to note that in the atmospheric chemistry community, SOA formation is considered to include both new particle formation and VOC condensation onto existing particles. However, from a remote sensing perspective, condensation on existing particles is usually classified as particle growth rather than new particle formation, especially as we often cannot

95 distinguish the condensation of volatile organic gases from hygroscopic growth. Therefore, we consider them here as distinct aging mechanisms. These and other processes often occur in combinations that may change on relatively short temporal and 
spatial scales; the factors that determine which mechanism(s) affect the observable particle properties most are currently not well understood.

Based on our current knowledge of the factors controlling smoke particle properties, we might expect that geographic and meteorological conditions are important drivers in particle speciation and plume chemistry. However, to date there have been no global observational studies to help us constrain these relationships on a large scale. As wildfire frequency and severity are expected to increase with global warming, it is becoming increasingly important to improve our understanding of the factors controlling wildfire smoke particle properties. Most current chemical transport and climate models do not discriminate between BIS and BrS, despite their distinct optical and physical properties, which can therefore produce different environmental consequences [Feng et al., 2013; Samset et al., 2018]. Models are also uncertain about the role wildfire smoke plays in aerosol-cloud interactions. Better characterization of fire-generated particles is thus a pressing issue for many modeling efforts. Constraining particle properties and the dominant aging mechanisms in terms of fuel properties and meteorological conditions would contribute greatly towards this goal. Such insight would also have consequences for air quality modeling, as particle speciation and evolution are important factors in determining the atmospheric lifetime of harmful smoke particulates.

Recently developed techniques allow for a better understanding of previously unconstrained wildfire plume heights and particle properties from space, with the potential to characterize wildfire smoke globally by exploring the factors that control emitted and evolved BB particle properties (e.g., Kahn [2020]). These satellite products will achieve their greatest value when applied broadly, to numerous cases over entire ecosystems, yielding statistically robust patterns of smoke-plume behavior. The work presented here takes some first steps toward providing regional constraints on BB particle properties and their dependence on meteorology, vegetation, and burning conditions from space-based observations. Specifically, this study relies on measurements from the Multi-Angle Imaging Spectrometer (MISR) aboard the NASA Earth Observing System's Terra satellite, in conjunction with the MISR Research Aerosol (RA) retrieval algorithm to assess BB particle properties and the MISR Interactive Explorer (MINX) tool to determine plume height and associated wind vectors. These methods have been thoroughly validated against near-coincident in situ observations of smoke plumes from the Biomass Burning Observation Project (BBOP) and the Fire Influence on Regional to Global Environments Experiment - Air Quality (FIREXAQ) field campaigns [Junghenn Noyes et al., 2020a, 2020b]. These experiments demonstrated the strengths and limitations of MISR's ability to: 1) constrain particle size, shape, and light-absorption properties, and to do so at finer spatial scales and in greater detail than other currently orbiting satellite instruments, 2) map the entire plume, providing context for field observations that are usually only able to observe a disjointed, small percentage of the plume area, and 3) narrow down the likely suite of aging mechanisms acting upon the plume particles at various downwind distances. In both studies cited above, the RA successfully mapped patterns in smoke particle size and light-absorption, with some small exceptions that can be attributed to differences in sampling between the satellite and aircraft and/or the time differences between observations. With the RA we were also able to infer specific aging mechanisms or burning conditions (e.g., oxidation, secondary particle formation, gravitational settling, etc.), and our results are supported by the in situ data. 
In the current work we apply the MISR tools to a large ensemble of fire plumes across Canada and Alaska that were not constrained by field observations, in order to: 1) characterize emitted and evolved smoke particle properties; 2) identify patterns and establish relationships among fuel type, burning conditions, and ambient meteorology, and plume properties; and 3) infer the relevant aging mechanisms from the observed patterns. To this end, we compare the retrieved patterns associated with different ecosystems and environmental conditions with an array of other data, including fire radiative power (FRP) and land cover type from the MODerate resolution Imaging Spectroradiometer (MODIS), drought severity from the North American Drought Monitor (NADM), and MERRA-2 meteorological reanalysis. Trends in particle properties are also studied in the context of smoke age estimates derived from MINX wind vectors. Statistical analysis of the relationships among these observations provides insight into the factors controlling BB particle type emissions and the associated aging processes, directly addressing key elements missing from current climate and air quality modeling efforts. This work is the first installation in a larger effort to constrain BB particle properties globally. Section 2 describes the data and methodology used in this study. Results and discussion are given in Sect. 3. Conclusions and plans for future work are presented in Sect. 4.

\section{Methodology}

\subsection{The MISR Instrument}

The MISR instrument is in a polar orbit aboard the NASA Earth Observing System's Terra satellite and has a swath width of $\sim 380 \mathrm{~km}$. As such, it samples locations at the equator approximately once every nine days, and every two days near the poles. MISR offers unique, multi-angle imagery from nine cameras viewing in the forward, nadir, and aft directions along the satellite orbit track, and four spectral bands observed at each angle centered at approximately $446 \mathrm{~nm}, 558 \mathrm{~nm}, 672$ $\mathrm{nm}$, and $866 \mathrm{~nm}$ [Diner et al., 1998]. The use of multiple camera angles makes it possible to retrieve height and motion vectors for clouds and aerosol plumes stereoscopically. This geometrical approach relies on the parallax of contrast features within the plume; therefore, deriving plume height with this method requires that plume features exhibit sufficient optical thickness and contrast relative to the surface. The MISR Interactive Explorer (MINX) software tool [Nelson et al., 2008, 2013] nicely accomplishes these retrievals and was used to derive stereo heights and associated wind vectors for plumes in this work. With MINX, the user manually defines the plume source, plume extent, and wind direction in the MISR imagery, from which MINX retrieves heights and winds locally. MINX has been used in numerous studies, including but not limited to retrieving heights and wind vectors for volcano, wildfire, and dust plumes [Junghenn Noyes et al., 2020a, 2020b; Val Martin et al., 2010, 2018; Scollo et al., 2012; Tosca et al., 2011; Kahn and Limbacher, 2012; Flower and Kahn, 2017a, 2017b, 2018, 2020a, 2020b; Yu et al., 2018; Vernon et al., 2018]. Under good retrieval conditions, MINX plume height estimates are accurate within $+/-0.5 \mathrm{~km}$ or better. In this work, we use the retrieved wind vectors, along with the distance from the source measured in the images, so that patterns in the evolution of downwind particle properties can be associated with general timescales in smoke plumes. The retrieved stereo heights are used to determine whether the smoke was injected above the planetary boundary layer (PBL), to study how plume height and thickness may inform the evolution of particle 
size distribution, and to find potential relationships between plume injection and burning intensity, as approximated by fire radiative power or FRP. In addition, the MINX analysis provides some initial insight into the quality of the viewing conditions, as plumes lacking a clear source or easily identifiable wind direction in the satellite imagery can result in lowconfidence height retrievals, and may need to be excluded from analysis. Lastly, if the MINX plume height is above about 2 $\mathrm{km}$, the MISR images sometimes must be co-registered at the median plume height rather than at ground level to maximize aerosol-type retrieval performance when subsequently using the RA to derive particle properties. For this work, about $50 \%$ of the MINX retrievals were obtained through the MISR Plume Height Project archive [Nelson et al., "MISR Plume Height Project"].

Information relating to aerosol type was retrieved using the MISR research aerosol retrieval algorithm (RA) [Limbacher and Kahn, 2014, 2019], which compares the multi-angle, multi-spectral MISR observations with simulated topof-atmosphere (TOA) reflectances to retrieve aerosol optical depth (AOD) and to constrain particle extinction Ångström exponent (ANG; calculated from measurements at 446 and $866 \mathrm{~nm}$ ), particle single scattering albedo (SSA) and its spectral slope, and particle shape (spherical vs. non-spherical) for each $\sim 1.1-\mathrm{km}$ MISR pixel. The intended use of the RA (e.g., for pollution studies, or for wildfire, volcano, or dust plumes) governs the specific set of aerosol components to be included in the algorithm climatology, with each aerosol "type" having a different range of microphysical properties. The particle property information content of MISR observations is qualitative, amounting to three to five size bins (e.g., "small," "medium," and "large"), two to four bins in SSA, and spherical vs. randomly oriented non-spherical particle shapes, under good but not necessarily ideal retrieval conditions [Kahn et al., 2010; Kahn and Gaitley, 2015]. For our wildfire studies, the RA includes one non-spherical component (a soil or dust grain optical analogue, based on an optical model derived in Lee et al. [2017]) and 16 spherical components ranging in size and SSA values (Table 1). For light-absorbing aerosols, particle type is further categorized based on the spectral variation in absorption across the visible and near-infrared spectrum, where "flat" aerosols display little to no wavelength dependence and are representative of typical urban pollution or BlS, whereas "steep" aerosols exhibit greater absorption at shorter wavelengths and are more similar to BrS from wildfire smoke [Chen et al., 2008; Samset et al., 2018; Limbacher and Kahn, 2014; Andreae and Gelencser, 2006]. For each MISR pixel, the RA calculates AOD values for each particle component to create a best-guess mixture representing the aerosol plume composition, such that the simulated TOA reflectances best match those observed in the MISR multi-angle, multi-spectral measurements. This method has already been used for global aerosol typing [Kahn and Gaitley, 2015] and for characterizing particle type in volcanic and wildfire plumes [Toon et al., 2016; Kahn and Limbacher, 2012; Flower and Kahn, 2018, 2020a, 2020b; Junghenn Noyes et al., 2020a; 2020b].

Particle property information derived from MISR and any other passive remote-sensing data is based on columneffective, optical measurements rather than from direct sampling. In this and related works we therefore refer to the RA measurements of particle size and light-absorption as the retrieved effective particle size (REPS; $\mu \mathrm{m})$ and the retrieved effective particle absorption (REPA; dimensionless), respectively. These terms help reflect both the measured content and the limitations of the retrieved quantities. We use along-plume changes in AOD, REPS, and REPA combined with available 
meteorological data, MINX stereo heights, and age estimates to help constrain the relevant aging mechanisms for plumes observed under good retrieval conditions. (Retrieved particle property information is reduced when the mid-visible AOD falls below about 0.15 or 0.2 , but this is generally not a concern for the well-defined smoke plumes.) For example, decreasing AOD accompanied by decreasing REPS downwind might indicate size-selective dilution, whereas uniform particle deposition would feature decreasing AOD accompanied by relatively constant REPS. Similarly, constant AOD accompanied by increasing REPS downwind might signify particle aggregation, whereas constant or increasing AOD accompanied by decreasing REPS could reflect the formation of secondary aerosols. These and other patterns have been observed with MISR in volcanic and smoke plumes (e.g., Flower and Kahn [2020a, 2020b]; Junghenn Noyes et al. [2020a, 2020b]).

Table 1. MISR components from Research Aerosol (RA) retrieval results, using the algorithm version summarized in Sect. 2.1, with a 774-mixture climatology. SSA — single scattering albedo.

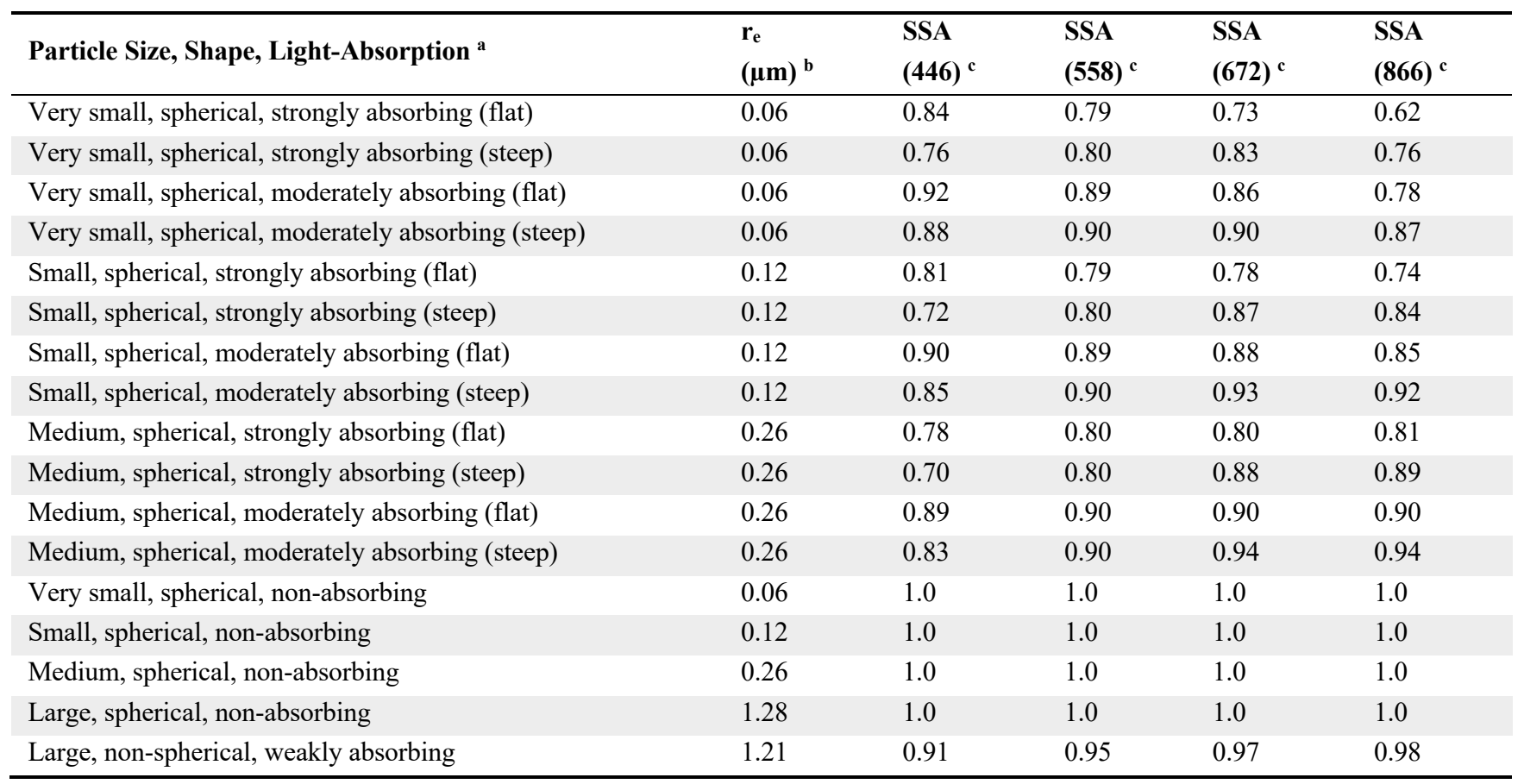

${ }^{a}$ Particle type includes four elements: size — very small (VSm), small (Sm), medium (Me), and large (La); shape — spherical (Sph) or non-spherical (Nsph); light-absorption - non-absorbing (Nab), weakly absorbing (Wab), moderately absorbing (Mab), and strongly absorbing (Sab); spectral light-absorption profile - equal in all spectral bands (flat), or varying between spectral bands (steep).

${ }^{\mathrm{b}}$ Each component has a designated effective radius $\left(\mathrm{r}_{\mathrm{e}}\right)$.

${ }^{\mathrm{c}}$ Wavelengths are given in $\mathrm{nm}$.

The operation of the RA is described by Limbacher and Kahn [2014, 2019]. Recently, several advancements were made to the RA that increase particle property sensitivity, especially for over-land retrievals, and are leveraged in this work (see Junghenn Noyes et al., [2020a, 2020b]). We have also introduced a revised particle climatology in the RA that is more 
focused on biomass burning plumes than in previous versions, such as the one used by Flower and Kahn [2017a, 2017b, 2018, 2020a, 2020b]. Details of the 17-component optical and physical properties included are given in Table 1. In general, light-absorbing particles are classified as either strongly light-absorbing (mid-visible SSA 0.80), moderately light-absorbing (SSA 0.90), or weakly light-absorbing (SSA 0.95). Particle size is classified as either "very small" (effective radius $\mathrm{r}_{\mathrm{e}} \sim 0.06$ $\mu \mathrm{m})$, "small" ( $\left.\mathrm{r}_{\mathrm{e}} \sim 0.12 \mu \mathrm{m}\right)$, "medium" $\left(\mathrm{r}_{\mathrm{e}} \sim 0.26 \mu \mathrm{m}\right)$, or "large" $\left(\mathrm{r}_{\mathrm{e}}>\sim 1.2 \mu \mathrm{m}\right)$, where particles are assumed to be lognormally distributed. The uncertainty in the retrieved AOD (and therefore the constraints on the particle properties) becomes large once AOD exceeds about 7, as the surface is no longer visible to MISR, and so for this work we only consider RA results in pixels with AOD at or below this threshold.

\subsection{Experiment Setting and Case Selection}

Suitable fires within the $\sim 380 \mathrm{~km}$ MISR swath were identified from imagery and thermal anomalies in coincident MODIS/Terra data. The MODerate resolution Imaging Spectroradiometer (MODIS) instrument has a cross-track swath width of $2330 \mathrm{~km}$ that provides global coverage every 1 to 2 days. Well-defined plumes of sufficient optical thickness, having a clear source and minimal cloud contamination, were favored for analysis. A total of 663 plumes, burning between 01 May and 30 September, and spanning the four years of this study (2016-2019), were analyzed. Table 2 quantifies the relative distribution of the observed plumes across year, month, regional location, and land cover type (the latter is discussed more in 2.3). For a small number of cases, fires in the United States were included in the study if they were part of a larger complex that burned mostly within Canada, and are classified here as belonging to the nearest Canadian province.

As Terra crosses the equator at $\sim 10: 30$ AM local time, the fires considered in this study are restricted to late-morning burns. Although burning usually peaks in the late afternoon, MISR observes a significant number of large, intense plumes, as has been shown in multiple studies previously (e.g., Val Martin et al. [2010]; Gonzalez-Alonso et al. [2019]) and with the success of the MISR Plume Height Project [Nelson et al., "MISR Plume Height Project"].

\subsection{MODIS Fire Radiative Power and Land Cover Type}

The MODIS/Terra Thermal Anomalies and Fire MOD14 product was used to identify fire pixel location and the 5minute FRP values at the time of MISR observation [Giglio and Justice, 2015]. Each plume was assigned a mutually exclusive set of hotspots based first on which ones fell inside the user-defined MINX boundary, and secondly by proximity to the boundary based on MODIS/Terra RGB imagery from NASA Worldview. Pixels identified with $0 \%$ confidence in the FRP product were ignored, except in cases where a plume did not contain any fire pixels with higher confidence, as these at least provide the locations of the burn and therefore land cover type (described below). For all but one plume, at least one fire pixel was detected. The MOD14 product has a spatial resolution of $1 \mathrm{~km}$, and reports FRP based on a detection algorithm that evaluates differences in the hotspot vs. background brightness temperature using the $4 \mu \mathrm{m}$ and $11 \mu \mathrm{m}$ channels [Giglio et al., 2003]. FRP is often used as a qualitative indicator of fire intensity; however, MODIS may 
underestimate FRP values under cloud or dense-smoke conditions, when the active fire only partly fills the MODIS pixel, as well as for plumes in the smoldering phase that can exhibit lower radiant emissivity and therefore lower FRP values [Kahn et al., 2008].

We systematically associated the fire pixels with annual $0.5-\mathrm{km}$ land cover type data from the MCD12Q1 product [Friedl and Sulla-Menashe, 2019], which includes data from the MODIS instruments on both the Terra and Aqua satellites.

255 We used this information to classify the type(s) of vegetation burning in each hotspot using: a) the International GeosphereBiosphere Programme (IGBP) classification, which generally categorizes vegetation types based on canopy height, percent cover, woody vs. herbaceous, and evergreen vs. deciduous; and b) the FAO-Land Cover Classification System (LCCS) surface hydrology layer classification, which provides less specific information but contains several additional categories compared to IGBP. It is important to note that the MODIS land cover type products do not provide sufficient detail for determining the actual fuel type consumed by fires, which also depends on a variety of other factors (e.g., meteorology, preexisting burned area, seasonality, etc.). However, land cover and fuel type are highly correlated and we can use the MODIS product to make educated inferences as to the types of fuels that are present. (Future work will involve the use of more detailed fuel type information, as discussed in the Conclusions section).

Descriptions of the IGBP land cover types identified in this study are included in Table 3, and descriptions of all land cover types from both products can be found in Tables S1 and S2 in the Supplementary Materials. As the MCD12Q1 spatial resolution is finer than that of MOD14, some MODIS hotspots cover multiple land cover types, in which case we assigned land type as a split between the two that comprise the largest fractions of the fire pixel.

Table 2. Distributions of plume number, plume height, boundary layer height, location of burn, and dominant MODIS fuel type shown in three different ways: A) annually, B) monthly, and C) by fuel type. Note that an individual fire may burn in several biomes, so plumes in Table $3 \mathrm{C}$ are not in mutually exclusive categories. AGL — above ground level; PBL — planetary boundary layer. See footnotes for land type and region/territory abbreviations.

\begin{tabular}{|c|c|c|c|c|c|}
\hline & \multicolumn{5}{|c|}{ Table 2A. Plumes By Year } \\
\hline & 2016 & 2017 & 2018 & 2019 & Total \\
\hline No. Plumes & 71 & 319 & 114 & 159 & 663 \\
\hline Median Plume Height $(\mathrm{km})^{1}$ & 1.44 & 1.25 & 1.06 & 1.19 & 1.22 \\
\hline Max Plume Height $(\mathrm{km})^{2}$ & 2.26 & 1.97 & 1.84 & 2.21 & 2.07 \\
\hline No. $/ \%$ Above $2 \mathrm{~km}^{3}$ & $13 / 18.3$ & $35 / 10.9$ & $6 / 5.26$ & $15 / 9.43$ & $69 / 10.4$ \\
\hline No. $/ \%$ Above PBL ${ }^{4}$ & $24 / 33.8$ & $68 / 21.3$ & $17 / 14.9$ & $34 / 21.38$ & $143 / 21.57$ \\
\hline Median PBL Height ${ }^{5}$ & 1.69 & 1.61 & 1.52 & 1.47 & 1.57 \\
\hline Dominant Land Types Burned ${ }^{6}$ & $\begin{array}{c}\text { W. Sav. } \\
\text { Sav. }\end{array}$ & $\begin{array}{c}\text { W. Sav. } \\
\text { Sav. }\end{array}$ & $\begin{array}{l}\text { W. Sav. } \\
\text { Evergreen }\end{array}$ & $\begin{array}{c}\text { W. Sav. } \\
\text { Sav. }\end{array}$ & $\begin{array}{c}\text { W. Sav. } \\
\text { Sav. }\end{array}$ \\
\hline Dominant Regions $^{7}$ & $\begin{array}{c}\text { Sask. }(28 \%) \\
\text { AK }(26 \%)\end{array}$ & $\begin{array}{c}\text { NWT }(39 \%) \\
\text { BC }(24 \%)\end{array}$ & $\begin{array}{l}\text { BC }(70 \%) \\
\text { Yuk. }(9 \%)\end{array}$ & $\begin{array}{l}\text { AK }(47 \%) \\
\text { Alb. }(25 \%)\end{array}$ & $\begin{array}{c}\text { BC }(25 \%) \\
\text { NWT }(21 \%)\end{array}$ \\
\hline
\end{tabular}




\begin{tabular}{|c|c|c|c|c|c|}
\hline & \multicolumn{5}{|c|}{ Table 2B. Plumes By Month, Aggregated Over Four Years } \\
\hline & May & June & July & August & Sept \\
\hline No. Plumes & 39 & 51 & 259 & 264 & 50 \\
\hline Median Plume Height $(\mathrm{km})^{1}$ & 1.39 & 1.56 & 1.29 & 1.16 & 0.739 \\
\hline Max Plume Height $(\mathrm{km})^{2}$ & 2.21 & 2.69 & 2.09 & 1.89 & 1.71 \\
\hline No. $/ \%$ Above $2 \mathrm{~km}^{3}$ & $7 / 17.9$ & $11 / 21.6$ & $27 / 10.4$ & $24 / 9.09$ & $0 / 0.00$ \\
\hline No. $/ \%$ Above PBL $^{4}$ & $17 / 43.59$ & $18 / 35.29$ & $51 / 19.69$ & $51 / 19.32$ & $6 / 12.00$ \\
\hline Median PBL Height ${ }^{5}$ & 1.44 & 1.71 & 1.63 & 1.54 & 1.07 \\
\hline Median FRP $\left(\mathrm{W} / \mathrm{m}^{2}\right)^{8}$ & 54.13 & 49.09 & 46.39 & 49.38 & 37.97 \\
\hline Median PBL-Top Stability $(\mathrm{K} / \mathrm{km})^{9}$ & 2.61 & 3.95 & 4.43 & 4.33 & 6.51 \\
\hline Dominant Land Types Burned ${ }^{6}$ & $\begin{array}{c}\text { W. Sav } \\
\text { M.F. }\end{array}$ & $\begin{array}{c}\text { W. Sav. } \\
\text { Sav. }\end{array}$ & $\begin{array}{c}\text { Sav. } \\
\text { W. Sav. }\end{array}$ & $\begin{array}{c}\text { W. Sav. } \\
\text { Sav. }\end{array}$ & $\begin{array}{l}\text { W. Sav. } \\
\text { Evergreen }\end{array}$ \\
\hline Dominant Regions ${ }^{7}$ & $\begin{array}{l}\text { Alb. }(54 \%) \\
\text { Ont. }(21 \%)\end{array}$ & $\begin{array}{l}\text { AK }(47 \%) \\
\text { Yuk. }(14 \%)\end{array}$ & $\begin{array}{c}\text { AK }(34 \%) \\
\text { NWT }(22 \%)\end{array}$ & $\begin{array}{c}\text { BC }(48 \%) \\
\text { NWT }(31 \%)\end{array}$ & $\begin{array}{c}\text { Sask. }(42 \%) \\
\text { BC }(36 \%)\end{array}$ \\
\hline
\end{tabular}

\begin{tabular}{|c|c|c|c|c|}
\hline & \multicolumn{4}{|c|}{ Table 2C. Plumes By Land Type, Aggregated Over Four Years } \\
\hline & Evergreen & Mixed Forests & Deciduous & Woody Savanna \\
\hline No. Plumes & 205 & 39 & 3 & 459 \\
\hline Median Plume Height $(\mathrm{km})^{1}$ & 1.19 & 1.22 & 0.584 & 1.23 \\
\hline Max Plume Height $(\mathrm{km})^{2}$ & 2.11 & 2.04 & 1.71 & 2.07 \\
\hline No. / \% Above $2 \mathrm{~km}^{3}$ & $24 / 11.7$ & $5 / 12.8$ & $0 / 0.0$ & $53 / 11.5$ \\
\hline \multirow[t]{2}{*}{ No. $/ \%$ Above PBL ${ }^{4}$} & $42 / 20.5$ & $8 / 20.5$ & $0 / 0.0$ & $98 / 21.4$ \\
\hline & Savanna & Grassland & Shrubland & Wetlands \\
\hline No. Plumes & 312 & 80 & 62 & 2 \\
\hline Median Plume Height $(\mathrm{km})^{1}$ & 1.30 & 1.23 & 1.17 & 1.52 \\
\hline Max Plume Height $(\mathrm{km})^{2}$ & 2.13 & 2.22 & 2.06 & 2.07 \\
\hline No. $/ \%>2 \mathrm{~km}^{3}$ & $39 / 12.5$ & $8 / 10.0$ & $4 / 6.45$ & $0 / 0.0$ \\
\hline No. $/ \%$ Above PBL ${ }^{4}$ & $82 / 26.28$ & $20 / 25.0$ & $13 / 21.0$ & $1 / 50.0$ \\
\hline
\end{tabular}

${ }^{1}$ MINX-derived median plume heights AGL, averaged across the given category

${ }^{2}$ MINX-derived maximum plume heights AGL, averaged across the given category

$280{ }^{3}$ Median plume height must be $>2.0 \mathrm{~km}$ AGL

${ }^{4}$ Median plume height must be $>$ PBL height $+100 \mathrm{~m}$

${ }^{5}$ AGL; From MERRA-2 reanalysis data

${ }^{6}$ M.F. $=$ Mixed Forests; Sav. = Savannas, W. Sav. = Woody Savannas

${ }^{7} \mathrm{AK}=$ Alaska; Alb. = Alberta; $\mathrm{BC}=$ British Columbia; NWT = Northwest Territories; Ont. = Ontario; Sask. = Saskatchewan

8 The median plume MODIS fire radiative power, averaged across the given category

${ }^{9}$ The estimated atmospheric stability at the top of the planetary boundary layer; from MERRA-2 reanalysis data 


\subsection{MERRA-2 Reanalysis}

For each plume, we obtain the estimated height of the planetary boundary layer (PBLH) from the Modern Era Retrospective-analysis for Research and Applications (MERRA-2) reanalysis model [Bosilovich et al., 2016; Gelaro et al., 2017]. The PBLH data are provided at $0.625^{\circ}$ longitude by $0.5^{\circ}$ latitude spatial resolution and hourly temporal resolution, so we choose the data point closest to the time and location of each fire plume origin.

We calculate atmospheric stability profiles for the column above each plume using 3-dimensional (3D) MERRA-2 meteorological data, reported every 6 hours at $0.667^{\circ}$ longitude by $0.5^{\circ}$ latitude spatial resolution. We consider atmospheric stability as the vertical gradient of potential temperature (Eq. 1) [Holton, 1992], where $\mathrm{S}$ is the stability value at the midpoint of two model levels, $\mathrm{d} \theta$ is the calculated difference in potential temperature between the levels, and $\mathrm{dz}$ is the difference in geopotential height. Potential temperature is calculated using Eq. 2 [Holton, 1992], where T and P are the atmospheric temperature and pressure, respectively, at altitude z. $P_{o}$ is the surface pressure (taken as $1000 \mathrm{mb}$ ), $R$ is the gas constant for dry air, and $C_{p}$ is the specific heat for dry air. For each plume, the temperature and pressure fields were interpolated to the time of MISR observation at the MERRA-2 point closest to the fire location. The height of the stable layer was defined as the height of the first maximum in the stability profile, so long as the stability is at least $1 \mathrm{~K} / \mathrm{km}$ larger than the layers above and below.

$$
\begin{aligned}
& S=\frac{d \theta}{d z} \\
& \theta=T\left(\frac{P_{o}}{P}\right)^{R / C_{p}}
\end{aligned}
$$

\subsection{North American Drought Monitor}

To evaluate the potential impacts of drought on smoke plume heights and particle properties, we leverage information on drought severity from the Canadian Drought Monitor (CDM) for plumes in Canada, and the United States Drought Monitor (USDM) for plumes in Alaska or just south of the US-Canada border. Both the CDM and USDM are part of the North American Drought Monitor (NADM) effort, a cooperative project between Canada, the United States, and Mexico that works to continually monitor drought extent and severity [Lawrimore et al., 2002] based on the methodology of the USDM [Svoboda et al., 2002]. This system uses a blend of drought indicators such as the Normalized Vegetation Index (NDVI), streamflow values, the Palmer Drought Index, and others used by the agriculture, forest, and water management sectors [Agriculture and Agri-food Canada]. The synthesis of these reports is analyzed by federal, state, and local academic scientists until a consensus is reached on the best representation of current drought conditions. Assessing drought in this blended manner may be preferable to using just one indicator, as different drought indices measure drought in different ways and no single index works under all circumstances [Heim, 2002]. The NADM index is based on a convergence of evidence from a wide variety of objective inputs and subjective adjustments based on local impacts. 
The NADM Drought classes range from D0 to D4, with D1 to D4 indicating moderate to exceptional drought and D0 representing abnormally dry conditions. The D0 class is not technically a drought classification, but might indicate if an area is vulnerable to or recovering from drought. Areas without an assigned drought class are considered to experience normal or wetter-than-normal conditions. The drought categories are based on the percent chance of those conditions occurring over a 100-year period, classified as follows:

- D0 (Abnormally Dry) - represents an event that occurs once every 3-5 years

- D1 (Moderate Drought) - represents at event that occurs every 5-10 years

- D2 (Severe Drought) - represents an event that occurs every 10-20 years

- D3 (Extreme Drought) - represents an event that occurs every 20-25 years

- D4 (Exceptional Drought) - represents an even that occurs every 50 years [Agriculture and Agri-food Canada]

The USDM is a collaborative effort between the National Drought Mitigation Center (NDMC), the U.S. Department of Agriculture (USDA), and the National Oceanic and Atmospheric Administration (NOAA). It reports the state of drought on a weekly basis and can be accessed at https://droughtmonitor.unl.edu/. The CDM is developed by the Department of Agriculture and Agri-food's (AAFC) National Agroclimate Information Service (NAIS) and reports on a monthly basis. The data can be accessed at https://open.canada.ca/data/en/dataset/292646cd-619f-4200-afb1-8b2c52f984a2.

Table 3. Definitions of the land cover types detected in this study, from the MODIS International Geosphere-Biosphere Programme 335 (IGBP) classification method

\begin{tabular}{l|l}
\hline Land Cover Type & Description \\
\hline \hline Evergreen Needleleaf Forests & Dominated by evergreen conifer trees (canopy $>2 \mathrm{~m})$. Tree cover $>60 \%$. \\
\hline Evergreen Broadleaf Forests & Dominated by evergreen broadleaf and palmate trees (canopy $>2 \mathrm{~m})$. Tree cover $>60 \%$. \\
\hline Deciduous Needleleaf Forests & Dominated by deciduous needleleaf (larch) trees (canopy $>2 \mathrm{~m})$. Tree cover $>60 \%$. \\
\hline Deciduous Broadleaf Forests & Dominated by deciduous broadleaf trees (canopy $>2 \mathrm{~m})$. Tree cover $>60 \%$. \\
\hline Mixed Forests & $\begin{array}{l}\text { Dominated by neither deciduous nor evergreen }(40-60 \% \text { of each) tree type }(\text { canopy }>2 \mathrm{~m}) . \text { Tree } \\
\text { cover }>60 \% .\end{array}$ \\
\hline Closed Shrublands & Dominated by woody perennials $(1-2 \mathrm{~m}$ height $)>60 \%$ cover. \\
\hline Open Shrublands & Dominated by woody perennials $(1-2 \mathrm{~m}$ height) $10-60 \%$ cover. \\
\hline Woody Savannas & Tree cover $30-60 \%$ (canopy $>2 \mathrm{~m})$. \\
\hline Savannas & Tree cover $10-30 \%$ (canopy $>2 \mathrm{~m})$. \\
\hline Grasslands & Dominated by herbaceous annuals $(<2 \mathrm{~m})$. \\
\hline Permanent Wetlands & Permanently inundated lands with $30-60 \%$ water cover and $>10 \%$ vegetated cover. \\
\hline
\end{tabular}




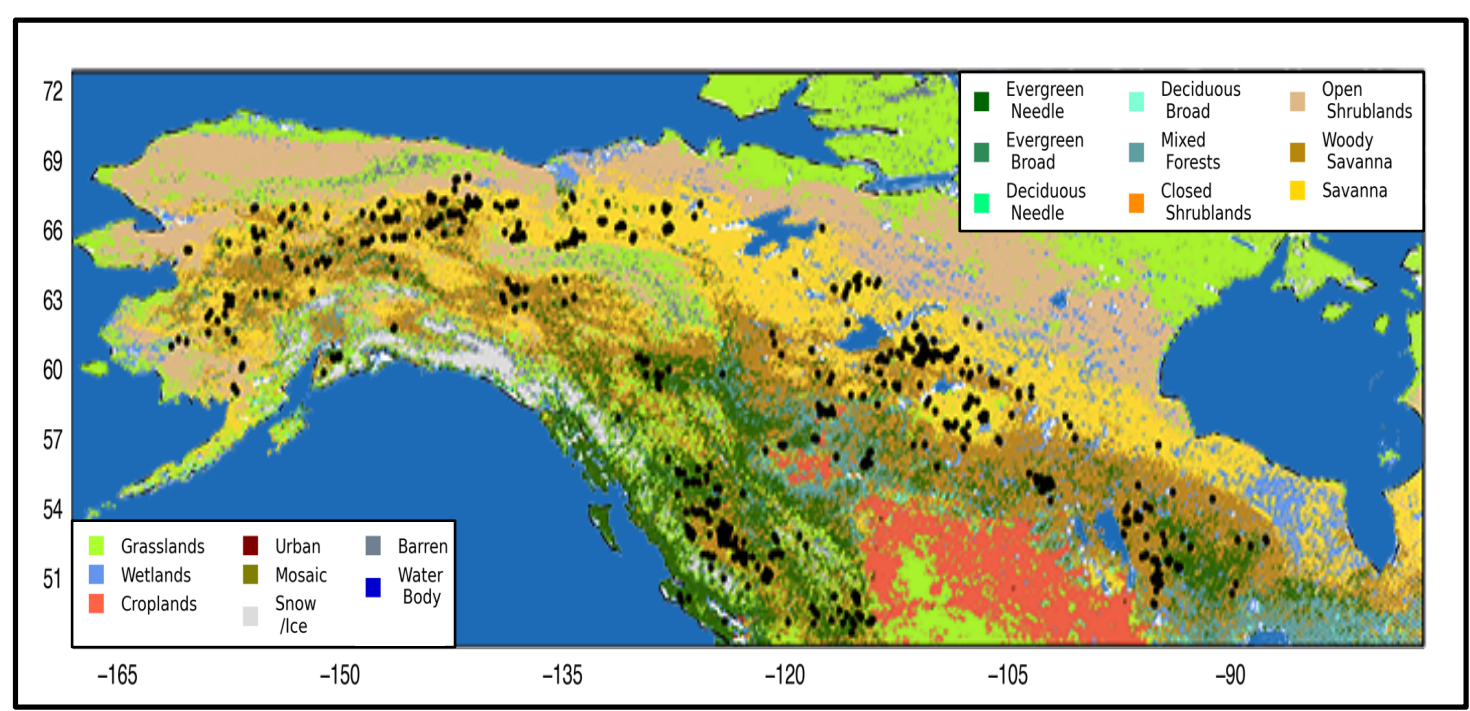

340 Figure 1. Map of all plumes used in this study (black dots) overlayed on the 2017 MODIS IGBP land cover types.

\section{Results and Discussion}

Figure 1 maps the plumes used this study over Canada and Alaska, superposed on the 2017 MODIS IGBP land cover types, and Table 2 shows how these plume observations are distributed by year, month, and MODIS land cover type. The largest number of plumes in our study set was recorded in 2017 (48\% of the total), whereas the smallest number was recorded in 2016 (11\%). Plumes were observed mostly in British Columbia, the Northwest Territories, and Alaska, although a significant number of fires occurred in other provinces and territories. (No suitable plumes were found in Nunavut or east of Ontario.) Most plumes were observed in July and August (79\%), at the peak burning season, and during abnormally dry or drought conditions (65\%). Woody savanna (30-60\% tree cover, canopy $>2 \mathrm{~m}$ ) was the most common land cover type, followed closely by savanna (tree cover $10-30 \%$, canopy $>2 \mathrm{~m}$ ) and evergreen forest (tree cover $>60 \%$, canopy $>2 \mathrm{~m}$, dominated by evergreen conifer, broadleaf, or palmate trees). A smaller, but still significant, number of plumes were from fires that at least partially burned in grassland (dominated by herbaceous annuals $<2 \mathrm{~m}$ tall), mixed forest (tree cover $>60 \%$, canopy $>2 \mathrm{~m}$, comprised of $40-60 \%$ each of deciduous and evergreen trees), and open shrubland (10-60\% cover, dominated by woody perennials $1-2 \mathrm{~m}$ tall). (Table 3 provides definitions for all land types detected in this study).

We combine the MODIS land cover types into three broad categories to classify the observed fires: 1) "Forest" fires (denoted with an "F" where appropriate), which contain any number of MODIS hotspots located in evergreen, deciduous, or mixed forests; 2) "Woody" fires (W), which do not burn in forest but have at least $30 \%$ of their hotspots located in woody savanna and up to $70 \%$ located in savanna, grassland, or shrubland; and 3) "Grassy" fires (G), for which there are also no forest hotspots, but at least $70 \%$ are located in savannas, grasslands, or shrublands, and no more than $30 \%$ are located in woody savanna. This categorization captures the range of fuel sizes generally included in most classification models (e.g., 
Ottmar et al. [2001]; Scott and Burgan [2005]). Forest plumes are the most likely to contain coarse, woody fuels that tend to maintain their moisture over longer periods of time and often tend to burn in the smoldering phase, whereas Grassy plumes are likely dominated by fine fuels that dry out quickly and burn mostly in the flaming phase [Ottmar, 2001; Urbanski, 2013]. The W plume category represents an intermediate step between these two.
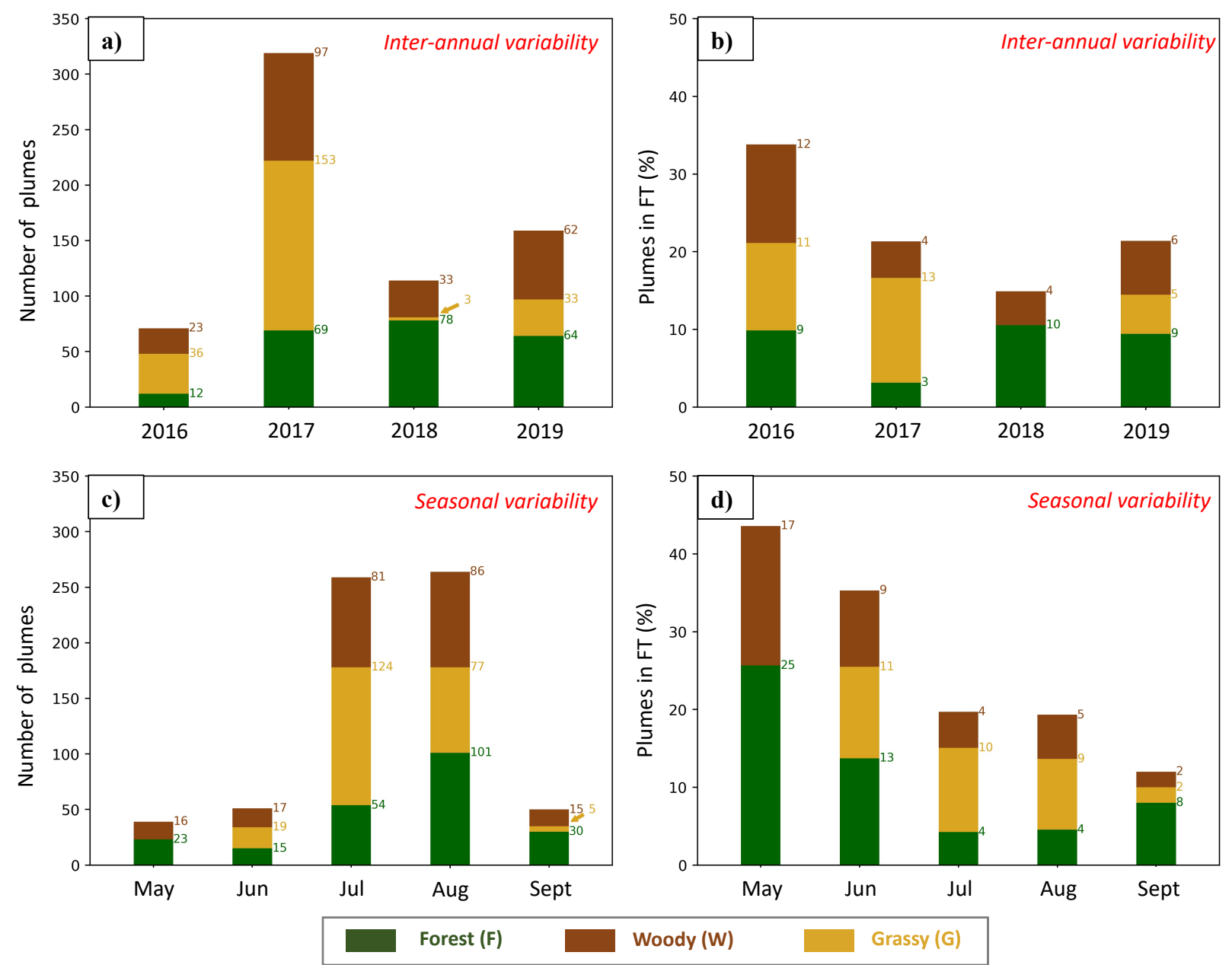

Figure 2. Seasonal and inter-annual variability of plume number $(a, c)$ and percent of those plumes in the free troposphere (FT) (b, d). Each bar is divided by color according to the relative contribution from each of the three fire types in the given month or year, with quantitative annotations. For example, 39 plumes were identified in the month of May (panel c), 16 of which were $\mathrm{W}$ fires and 23 were F fires. Of the 39 fires that month, $42 \%$ were in the FT (17\% that were classified at W fires, and $25 \%$ that were classified as F fires) (panel d). A plume is considered to be in the FT if its median height is $100 \mathrm{~m}$ greater than the PBL height as defined in the MERRA-2 dataset.

There is important seasonal variability in the observed fire types, with $G$ plumes comprising nearly half of all those observed in July, and almost none in the colder months of May and September (Figure 2c). In contrast, despite the overall lower plume numbers in these months, F plumes are dominant in May and September. This dichotomy can be traced to the 
latitude of the burns $-87 \%$ of G plumes were observed in the Northwest Territories, Alaska, or the Yukon, the three northernmost areas of study, dominated largely by grassy fuels (particularly savannas). Among F plumes, $64 \%$ burned to the south in either British Columbia or Alberta, dominated by forests (Figure 1). The delay of peak fire season in the colder regions limits $\mathrm{G}$ plume occurrence until later in the summer or even early fall.

Below we present our analysis of the significant trends in plume heights, particle properties, FRP, and atmospheric conditions, with a focus on the difference between the three broad fire types where possible. Table 4 provides a statistical summary of some of the main smoke plume parameters for each fire type, which are explored in more detail in subsequent figures. Where appropriate, we perform independent t-tests to assess if observed differences between fire types are statistically significant ( $\mathrm{p}$-value less than 0.05 ). We find that in most cases, the differences are significant at least between two out of three fire types. This suggests that, although some differences are distinct, many patterns exist on a continuum

385 and results are likely somewhat dependent on how we define our fire types. For example, plumes in the F category may actually contain only a small percentage of forest. Likewise, tree-cover fraction varies widely within IGBP categories, and satellite data do not reflect the percent of woody/grass fuel actually consumed in a fire. This is why obtaining a large, statistical sampling is so important. Despite these caveats, many of the patterns we observe are consistent with current knowledge about fire properties, and the incorporation of additional datasets allows us to build upon this knowledge. The

390 MISR-retrieved particle properties allow us to infer some of the processes affecting particle emissions and evolution, especially when placed in the context of the land cover, FRP, drought level, and plume heights.

\subsection{Plume Height, Atmospheric Structure, and Fire Radiative Power Observations}

Plume heights vary considerably across the dataset, ranging from less than $0.2 \mathrm{~km}$ to just above $4.0 \mathrm{~km}$ AGL. In general, however, median plume heights are centered $\sim 1.2 \mathrm{~km}$, and maximum heights $\sim 2.0 \mathrm{~km}$, with only $\sim 10 \%$ of plumes having median heights above $2 \mathrm{~km}$. There is little month-to-month variability in plume heights except for a sharp drop in September $(p<0.05)$ and overall higher heights in June $(p<0.05$ except when compared to the month of May). The greater heights in June may be partly driven by higher PBL heights (Table 2b), whereas the lower heights in September are likely driven at least in part by colder temperatures at this time of year, which are not as conducive to intense burning and vertical plume development. The relatively lower median plume FRP in September $\left(38 \mathrm{~W} / \mathrm{m}^{2}\right)$ supports this interpretation (Table 2b). Overall, the highest-altitude plumes tend to be associated with the highest cumulative plume FRP values (i.e., the sum of all fire pixels in the plume, as distinct from the median value discussed above; Figure S1 in the Supplementary Materials), although there is considerable variability $\left(\mathrm{r}^{2}=0.37\right)$. This weak relationship is consistent with similar studies, including but not limited to Gonzalez-Alonso et al. [2019], and Val Martin et al. [2010, 2012].

The MERRA-2 data indicate PBL heights are centered $\sim 1.5 \mathrm{~km}$ above the surface on average, with the deepest

405 layers during the summer months of June, July, and August (small differences between these three months are not statistically significant, whereas the lower values in both May and September are distinct, with $\mathrm{p}<0.05$ ). We estimate $22 \%$ of plumes were injected above the boundary layer, using a conservative criterion that the median plume height must be at 
Table 4. Statistical summary of main smoke plume parameters for each fire category; FRP — fire radiative power; AOD—aerosol optical depth; ANG—Ångström exponent; SSA—single-scattering albedo; BIS—black smoke; BrS—brown smoke

\begin{tabular}{|c|c|c|c|c|c|c|}
\hline \multirow[b]{2}{*}{$\begin{array}{l}\text { Median Plume } \\
\text { MODIS per-pixel } \\
\text { FRP }\left(\mathrm{W} / \mathrm{m}^{2}\right)\end{array}$} & \multicolumn{2}{|c|}{ Forest Fires (F) } & \multicolumn{2}{|c|}{ Woody Fires (W) } & \multicolumn{2}{|c|}{ Grassy Fires $(G)$} \\
\hline & $\begin{array}{l}\text { mean: } \\
\pm \sigma: \\
\min : \\
\max :\end{array}$ & $\begin{array}{l}40.53 \\
\pm 33.93 \\
6.0 \\
229.6\end{array}$ & $\begin{array}{l}\text { mean: } \\
\pm \sigma: \\
\min : \\
\max :\end{array}$ & $\begin{array}{l}55.19 \\
\pm 59.81 \\
4.5 \\
367.0\end{array}$ & $\begin{array}{l}\text { mean: } \\
\pm \sigma: \\
\min : \\
\max :\end{array}$ & $\begin{array}{l}43.93 \\
\pm 43.38 \\
0.0 \\
306.5\end{array}$ \\
\hline $\begin{array}{l}\text { Cumulative Plume } \\
\text { MODIS FRP } \\
\left(\mathrm{W} / \mathrm{m}^{2}\right)\end{array}$ & $\begin{array}{l}\text { mean: } \\
\pm \sigma: \\
\text { min: } \\
\max :\end{array}$ & $\begin{array}{l}1575.5 \\
\pm 4115.4 \\
6 \\
40254.6\end{array}$ & $\begin{array}{l}\text { mean: } \\
\pm \sigma: \\
\min : \\
\max :\end{array}$ & $\begin{array}{l}829.86 \\
\pm 1805.1 \\
4.5 \\
20070.4\end{array}$ & $\begin{array}{l}\text { mean: } \\
\pm \sigma: \\
\min : \\
\max :\end{array}$ & $\begin{array}{l}682.67 \\
\pm 1295.1 \\
0 \\
11990.7\end{array}$ \\
\hline $\begin{array}{l}\text { MISR AOD } \\
(558 \mathrm{~nm})\end{array}$ & $\begin{array}{l}\text { mean: } \\
\pm \sigma: \\
\min : \\
\max :\end{array}$ & $\begin{array}{l}1.544 \\
\pm 1.025 \\
0.2012 \\
6.449\end{array}$ & $\begin{array}{l}\text { mean: } \\
\pm \sigma: \\
\min : \\
\max :\end{array}$ & $\begin{array}{l}1.450 \\
\pm 1.039 \\
0.2239 \\
6.270\end{array}$ & $\begin{array}{l}\text { mean: } \\
\pm \sigma: \\
\min : \\
\max :\end{array}$ & $\begin{array}{l}1.147 \\
\pm 0.7877 \\
0.1780 \\
5.697\end{array}$ \\
\hline $\begin{array}{l}\text { MISR ANG } \\
(558 \mathrm{~nm})\end{array}$ & $\begin{array}{l}\text { mean: } \\
\pm \sigma: \\
\min : \\
\max :\end{array}$ & $\begin{array}{l}1.65 \\
\pm 0.278 \\
0.912 \\
2.40\end{array}$ & $\begin{array}{l}\text { mean: } \\
\pm \sigma: \\
\min : \\
\max :\end{array}$ & $\begin{array}{l}1.70 \\
\pm 0.252 \\
0.983 \\
2.64\end{array}$ & $\begin{array}{l}\text { mean: } \\
\pm \sigma: \\
\min : \\
\max :\end{array}$ & $\begin{array}{l}1.75 \\
\pm 0.243 \\
0.746 \\
2.20\end{array}$ \\
\hline $\begin{array}{l}\text { MISR SSA } \\
(558 \mathrm{~nm})\end{array}$ & $\begin{array}{l}\text { mean: } \\
\pm \sigma: \\
\min : \\
\max :\end{array}$ & $\begin{array}{l}0.914 \\
\pm 0.0322 \\
0.799 \\
0.987\end{array}$ & $\begin{array}{l}\text { mean: } \\
\pm \sigma: \\
\min : \\
\max :\end{array}$ & $\begin{array}{l}0.909 \\
\pm 0.0295 \\
0.812 \\
0.984\end{array}$ & $\begin{array}{l}\text { mean: } \\
\pm \sigma: \\
\min : \\
\max :\end{array}$ & $\begin{array}{l}0.905 \\
\pm 0.0324 \\
0.799 \\
0.986\end{array}$ \\
\hline $\begin{array}{l}\text { MISR BIS Fraction } \\
\text { (\% Total AOD) }\end{array}$ & $\begin{array}{l}\text { mean: } \\
\pm \sigma: \\
\min : \\
\max :\end{array}$ & $\begin{array}{l}44.4 \\
\pm 21.3 \\
0.0 \\
100\end{array}$ & $\begin{array}{l}\text { mean: } \\
\pm \sigma: \\
\min : \\
\max :\end{array}$ & $\begin{array}{l}50.3 \\
\pm 20.6 \\
0.0 \\
96.2\end{array}$ & $\begin{array}{l}\text { mean: } \\
\pm \sigma: \\
\min : \\
\max :\end{array}$ & $\begin{array}{l}53.7 \\
\pm 21.0 \\
0.0 \\
100\end{array}$ \\
\hline $\begin{array}{l}\text { MISR BrS Fraction } \\
\text { (\% Total AOD) }\end{array}$ & $\begin{array}{l}\text { mean: } \\
\pm \sigma: \\
\min : \\
\max :\end{array}$ & $\begin{array}{l}7.05 \\
\pm 10.7 \\
0 \\
48.2\end{array}$ & $\begin{array}{l}\text { mean: } \\
\pm \sigma: \\
\min : \\
\max :\end{array}$ & $\begin{array}{l}6.39 \\
\pm 12.3 \\
0 \\
73.9\end{array}$ & $\begin{array}{l}\text { mean: } \\
\pm \sigma: \\
\min : \\
\max :\end{array}$ & $\begin{array}{l}4.71 \\
\pm 8.67 \\
0 \\
6.24\end{array}$ \\
\hline $\begin{array}{l}\text { MISR BIS Ratio } \\
(\%, \mathrm{BlS}: \mathrm{BlS}+\mathrm{BrS})\end{array}$ & $\begin{array}{l}\text { mean: } \\
\pm \sigma: \\
\min : \\
\max :\end{array}$ & $\begin{array}{l}85.6 \\
\pm 21.1 \\
0 \\
100\end{array}$ & $\begin{array}{l}\text { mean: } \\
\pm \sigma: \\
\min : \\
\max :\end{array}$ & $\begin{array}{l}88.1 \\
\pm 20.20 \\
0 \\
100\end{array}$ & $\begin{array}{l}\text { mean: } \\
\pm \sigma: \\
\min : \\
\max :\end{array}$ & $\begin{array}{l}91.0 \\
\pm 16.3 \\
0 \\
100\end{array}$ \\
\hline $\begin{array}{l}\text { MISR Nonabsorbing } \\
\text { Fraction } \\
\text { (\% Total AOD) }\end{array}$ & $\begin{array}{l}\text { mean: } \\
\pm \sigma: \\
\text { min: } \\
\max :\end{array}$ & $\begin{array}{l}34.6 \\
\pm 19.0 \\
0.0 \\
89.3\end{array}$ & $\begin{array}{l}\text { mean: } \\
\pm \sigma: \\
\min : \\
\max :\end{array}$ & $\begin{array}{l}31.8 \\
\pm 17.2 \\
0.0 \\
80.9\end{array}$ & $\begin{array}{l}\text { mean: } \\
\pm \sigma: \\
\min : \\
\max :\end{array}$ & $\begin{array}{l}29.2 \\
\pm 19.0 \\
0.0 \\
90.0\end{array}$ \\
\hline $\begin{array}{l}\text { MISR Nonspherical } \\
\text { Fraction } \\
\text { (\% Total AOD) }\end{array}$ & $\begin{array}{l}\text { mean: } \\
\pm \sigma: \\
\min : \\
\max :\end{array}$ & $\begin{array}{l}1.53 \\
\pm 4.86 \\
0 \\
40.0\end{array}$ & $\begin{array}{l}\text { mean: } \\
\pm \sigma: \\
\min : \\
\max :\end{array}$ & $\begin{array}{l}0.949 \\
\pm 3.30 \\
0 \\
21.7\end{array}$ & $\begin{array}{l}\text { mean: } \\
\pm \sigma: \\
\min : \\
\max :\end{array}$ & $\begin{array}{l}0.918 \\
\pm 3.38 \\
0 \\
9.4205\end{array}$ \\
\hline Number of Plumes & & 223 & & 215 & & 225 \\
\hline
\end{tabular}


least $100 \mathrm{~m}$ greater than the MERRA-2 PBL height to qualify as reaching to free troposphere (FT). There is a strong a seasonal component to the percent of plumes injected into the FT, steadily decreasing from month to month (Figure 2d, Table 2b). Warming temperatures increase PBL heights between May and June, which contributes to diminishing the likelihood that plumes will reach or exceed the bottom of the FT. Colder temperatures then decrease PBL heights in September, but plumes are the least likely to reach the FT during this month. This is likely at least partially driven by the differences in median plume FRP and plume heights discussed above - with consistent FRP and height values across June, July, and August, and a significant decrease in both come September. In addition, the strength of the temperature inversion at the top of the PBL is higher by $\sim 50 \%$ for plumes observed in September compared to earlier months, so atmospheric stability is likely an important factor constraining plume vertical development at this time of year (Table 2b). Figure 2 illustrates the seasonal variability of plume count and FT injection for all three fire types. We find no significant differences in the height of the boundary layer or AGL plume heights between the three types, which reinforces the idea that the ambient atmospheric structure combined with month-to-month variations in fire intensity are the dominant factors affecting wildfire plume rise in this region.

The smoke plumes injected into the free troposphere exhibit significantly larger FRP values than those confined to the boundary layer ( $\mathrm{p}<<0.05$ ), as might be expected. Median plume FRP values are centered at 66 and $42 \mathrm{~W} / \mathrm{m}^{2}$ for plumes above and below the top of the PBL, respectively, and cumulative FRP values are centered at $2502 \mathrm{vs.} 629 \mathrm{~W} / \mathrm{m}^{2}$. Plumes in the FT were also associated with relatively weaker temperature inversions at the top of the PBL compared to those not in the FT, although both mean values still indicate positive stability overall $(3.53 \mathrm{~K} / \mathrm{km}$ vs. $5.34 \mathrm{~K} / \mathrm{km}$ on average; $\mathrm{p}<<0.05)$. Together, this is consistent with the prevailing theory that a combination of fire intensity and atmospheric structure are the important factors modulating smoke plume vertical distribution. Of the plumes injected above the PBL, we found $48 \%$ were associated with distinct stable layer in the FT, and that plumes in the FT associated with stable layers exhibited lower heights than those not associated with stable layer layers (median heights of $1.83 \mathrm{~km}$ vs. $2.01 \mathrm{~km}$, and max heights of 2.87 vs. 3.17 $\mathrm{km} ; \mathrm{p}<0.05$ ). This follows from the results of Kahn et al. (2007) and Val Martin et al. (2010), in which it was shown that plumes injected above the boundary layer are largely concentrated within layers of relative stability in the FT.

\subsubsection{Differences Among Fire Types}

Fires identified in forest (F) tend to have cumulative plume FRP values that are essentially twice as high as other biomes $(\mathrm{p} \leq$ 0.014) (Table 4). The fire pixel count for these plumes (i.e., estimated fire area) likely drives the latter, as the average number of hotspots in these fires also outnumbers those in the other biomes $\sim 2: 1$. In fact, median per-pixel FRP for F fires is relatively low - only $40 \mathrm{~W} / \mathrm{m}^{2}$ on average, whereas both $\mathrm{W}$ and $\mathrm{G}$ fires exhibit somewhat higher median FRP values (55 and $44 \mathrm{~W} / \mathrm{m}^{2}$ on average, respectively), with $\mathrm{W}$ fires showing the largest FRP values. The median per-pixel FRP

440 values for the $\mathrm{F}$ fires we observed also never surpassed $230 \mathrm{~W} / \mathrm{m}^{2}$, whereas the $\mathrm{W}$ and $\mathrm{G}$ fires were observed to reach median FRP values of 367 and $307 \mathrm{~W} / \mathrm{m}^{2}$, respectively. This is consistent with previous studies of forest fires, that show a key fuel component is at or below the surface, where roots systems allow fires to burn deeper into soil layers compared to biomes 
dominated by finer fuels, such as grass and savanna (e.g., [Gonzalez- Alonzo et al., 2019]). The higher moisture content and lower oxygen availability in these subsurface layers are more conducive to smoldering than flaming fire phase, which leads

to higher smoke production (AOD) but lower radiant emissivity [Bertschi et al., 2003; Yokelson et al., 1997; GonzalezAlonso et al., 2019; van der Werf et al., 2010; Santoso et al., 2019]. Therefore, the comparatively lower average per-pixel FRP in F fires is consistent with a higher fraction of smoldering, and the higher FRP values in $\mathrm{W}$ and $\mathrm{G}$ fires are consistent with flaming conditions dominating. The idea that smoldering is favored in increasingly forested areas is also supported by significantly higher MISR AOD in F plumes $(\sim 1.54)$ and W plumes $(\sim 1.45)$ compared G $(\sim 1.15)$ plumes $(\mathrm{p}<0.001)$. (More on particle properties in subsequent sections). However, the differences in per-pixel FRP between $\mathrm{F}$ and $\mathrm{G}$ fires were not found to be statistically significant ( $\mathrm{p}=0.35$ ), whereas the differences between $\mathrm{W}$ fires and $\mathrm{F}$ or $\mathrm{G}$ fires are significant with $\mathrm{p}<=0.025$. It is possible that $\mathrm{W}$ fires have the highest median FRP because they have a lower fraction of smoldering than $\mathrm{F}$ fires, but burn longer than $\mathrm{G}$ fires, and therefore more completely fill the satellite fire pixels. This hypothesis might be tested with higher-spatial-resolution FRP observations than are available for the current study, e.g., from aircraft measurements.
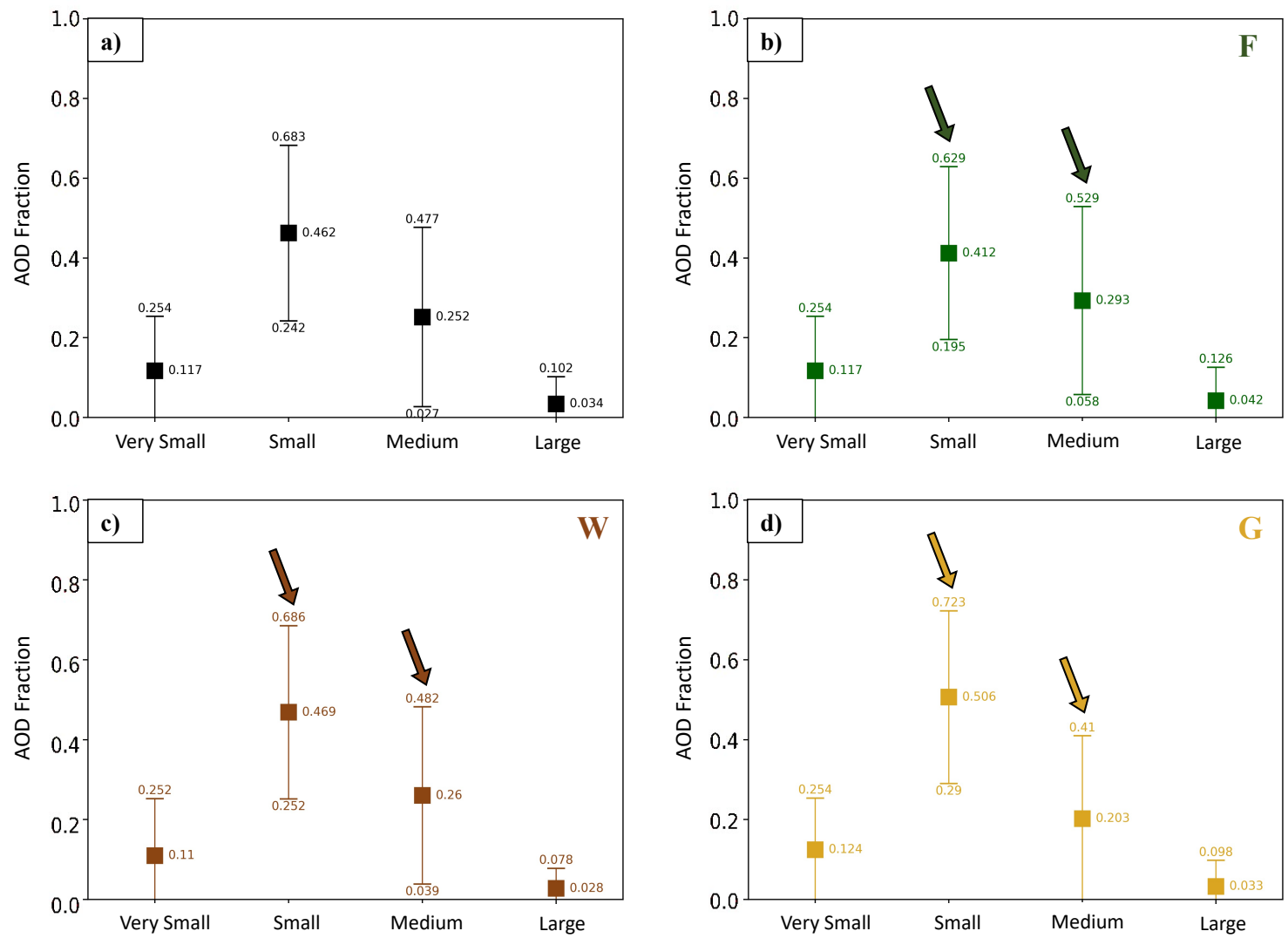

Figure 3. Particle size distributions in terms of each RA component's fractional contribution to the total AOD. All plume types are shown in (a), whereas panels (b-d) display color-coded results for individual plume types, denoted with the appropriate abbreviation in the upper right corner. Points represent the mean values and whiskers show the standard deviations. Arrows highlight the differences in the partitioning between small and medium particle fractions for the different plume types. 


\subsection{Overview of Smoke Particle Property Observations}

The observed smoke plumes exhibit a wide range of MISR-retrieved light-absorption properties, with median plume mid-visible SSA ranging all the way from $\sim 0.8$ to 1.0 , and fractional AOD of BIS and BrS ranging from 0 to 1 and 0 to $\sim 0.75$, respectively. Differences in plume REPA strongly drive the interpreted BlS content $\left(\mathrm{r}^{2}=0.7\right)$, whereas fractions of $\mathrm{BrS}$ are not correlated with retrieved light-absorption $\left(\mathrm{r}^{2}=0.1\right.$ : Figure S2 in the Supplementary Materials). MISR-retrieved particle size is somewhat less variable than light-absorption, with all plumes but one exhibiting median ANG of at least 1.0 (fine-mode particles), and the highest plume ANG just below 2.7. Most plumes have retrieved ANG values of 1.5-2.0. To help interpret ANG, we analyze each of the four particle size bins defined in the RA climatology (Table 1) in terms of their fractional contribution to the total AOD, where "very small" particles have an effective radius ( $\mathrm{r}_{\mathrm{e}}$ ) of $\sim 0.06 \mu \mathrm{m}$, "small" particles have $r_{e}$ of $\sim 0.12 \mu \mathrm{m}$, "medium" particles have $r_{e}$ of $\sim 0.26$, and "large" particles have $r_{e}>1.21 \mu \mathrm{m}$ (large particles include the non-spherical particle type as well as spherical types). The MISR REPS aggregates the contributions of these size components, and so the retrieved ANG, which might be more representative of the actual particle size differences (i.e., relative, not absolute), might not strictly identify one of these specific sizes. The actual particle size distributions are constrained within bins by the retrievals, and so discussing size in terms of these bins is helpful. The algorithm climatology contains these sizes to capture MISR sensitivity to particle size under good but not necessarily ideal retrieval conditions, based on theoretical analysis [Kahn et al., 2001] and subsequent field validation studies. As expected, analysis of the size components in this study indicates small and medium particles dominate the aerosol size distributions in most smoke plumes regardless of fire type, on average constituting $\sim 46 \%$ and $\sim 25 \%$ of the median plume AOD, respectively. Very small particles make up $\sim 11 \%$ of retrieved plume AOD on average, whereas large particles make up $\sim 3 \%$ (Figure $3 \mathrm{a}$ ). In most plumes, the fraction of non-spherical particles is low, constituting less than 5\% of the total retrieved AOD in $93 \%$ of plumes.

\subsection{Impact of Land Cover Type on Smoke Particle Properties}

Fires detected in forests (F) have the highest overall AOD values (1.54), whereas woody (W) and grassy (G) fires exhibit an average AOD of 1.45 and 1.15, respectively (Table 4). F plumes also have the highest fraction of non-spherical particles, with some plumes containing as much as $40 \%$ non-spherical particles, although on average these soil or dust analogs make up only $\sim 1.5 \%$ of the total AOD and differences in this fraction between plume types were not found to be statistically significant. However, the higher relative contribution of non-spherical particles in F plumes would partially account for their overall lower ANG (1.65) compared to W (1.70) and G (1.75) plumes. These differences in REPS, although small, are significant with $\mathrm{p} \leq 0.038$ in all three inter-biome comparisons. Figure 3 suggests the main driver of differences in particle size between plume types is the partitioning between small vs. medium particles, as the fractional contribution from very small particles is nearly identical across fire type, and differences in the fraction of large particles are only on the order of a few percent of total AOD. In F plumes, the contribution from medium particles is highest (29\%), although small particles still dominate $(41 \%)$. In $\mathrm{W}$ plumes, these fractions favor small particles significantly more $(47 \%, \mathrm{p}<<0.05)$. The 
greatest difference can be seen in G plumes, with nearly $51 \%$ of particles in the small category on average, and only a $20 \%$ contribution from medium particles. The extent to which these differences occur during emission vs. downwind aging are explored in Sect. 3.4.
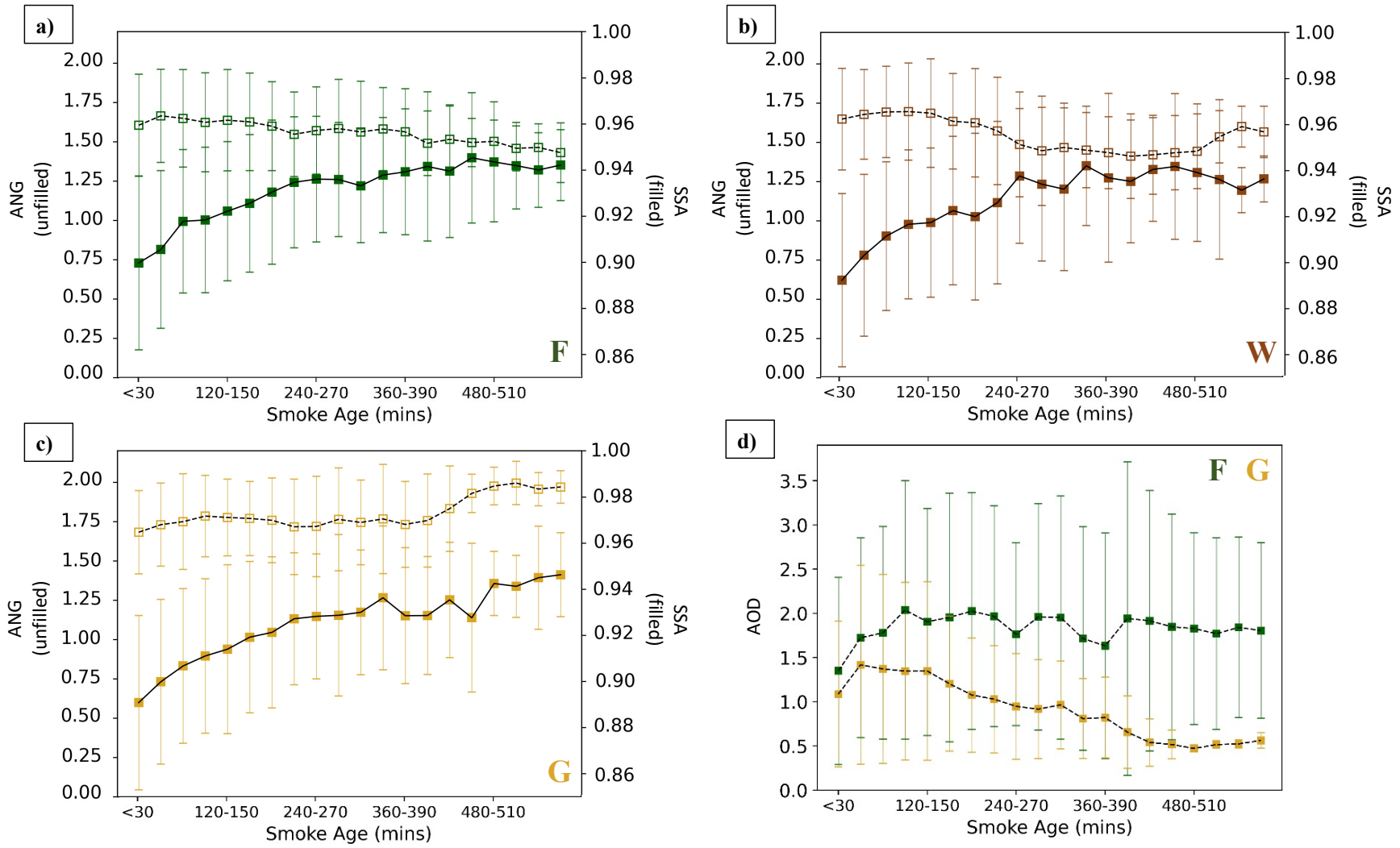

Figure 4. MISR mid-visible Ångström exponent (unfilled markers, dotted lines, left vertical axes) and single scattering albedos (filled markers, solid lines, right vertical axes) by smoke age for (a) Forest plumes, (b) Woody plumes, and (c) Grassy plumes. (Fuel type is indicated in the lower right of these plots.) In (d), the MISR mid-visible AOD is plotted by age for Forest and Grassy plumes. The points represent the mean values and the whiskers are standard deviations.

Particles are less light absorbing in F fires (SSA 0.914) compared to G fires (0.904) ( $\mathrm{p}=0.002)$, whereas W fires have SSA values between these two (0.909). All three fire types display similar ranges of possible values (Table 4). Analysis of the individual contributions from moderately to strongly light-absorbing components (BIS and BrS), weakly absorbing components (non-spherical), and non-absorbing components suggests that differences in the plume-averaged REPA manifest in a combination of: 1) the difference in the fractional AOD of non-absorbing vs. moderately to strongly absorbing aerosols; 2) to a lesser degree, the partitioning of BIS vs. BrS; and 3) the relative rate of change in particle type with plume age. To a certain degree, REPS also drives these factors, as larger particles having the same composition will have lower SSA. The first two factors can be seen in Table 4, with the sum of BIS and BrS higher in G fires compared to F fires, and especially 
high fractions of BlS in G fires and BrS in F fires ( $p<0.001$ in both cases). W fires are not considered statistically different from $\mathrm{F}$ or $\mathrm{G}$ fires in this regard, and exhibit values between these two. These findings are consistent with other studies, as smoldering fires (which are more frequent in forest compared to grassland and savanna fires) tend to produce higher fractions of brown carbon particles compared to flaming fires, but fires in savannas and grasslands emit larger fractions of black carbon [Chakrabarty et al., 2010, 2016; Petrenko et al., 2012]. The third factor driving inter-biome REPA differences is explored in Sect. 3.4, in our discussion of particle aging.
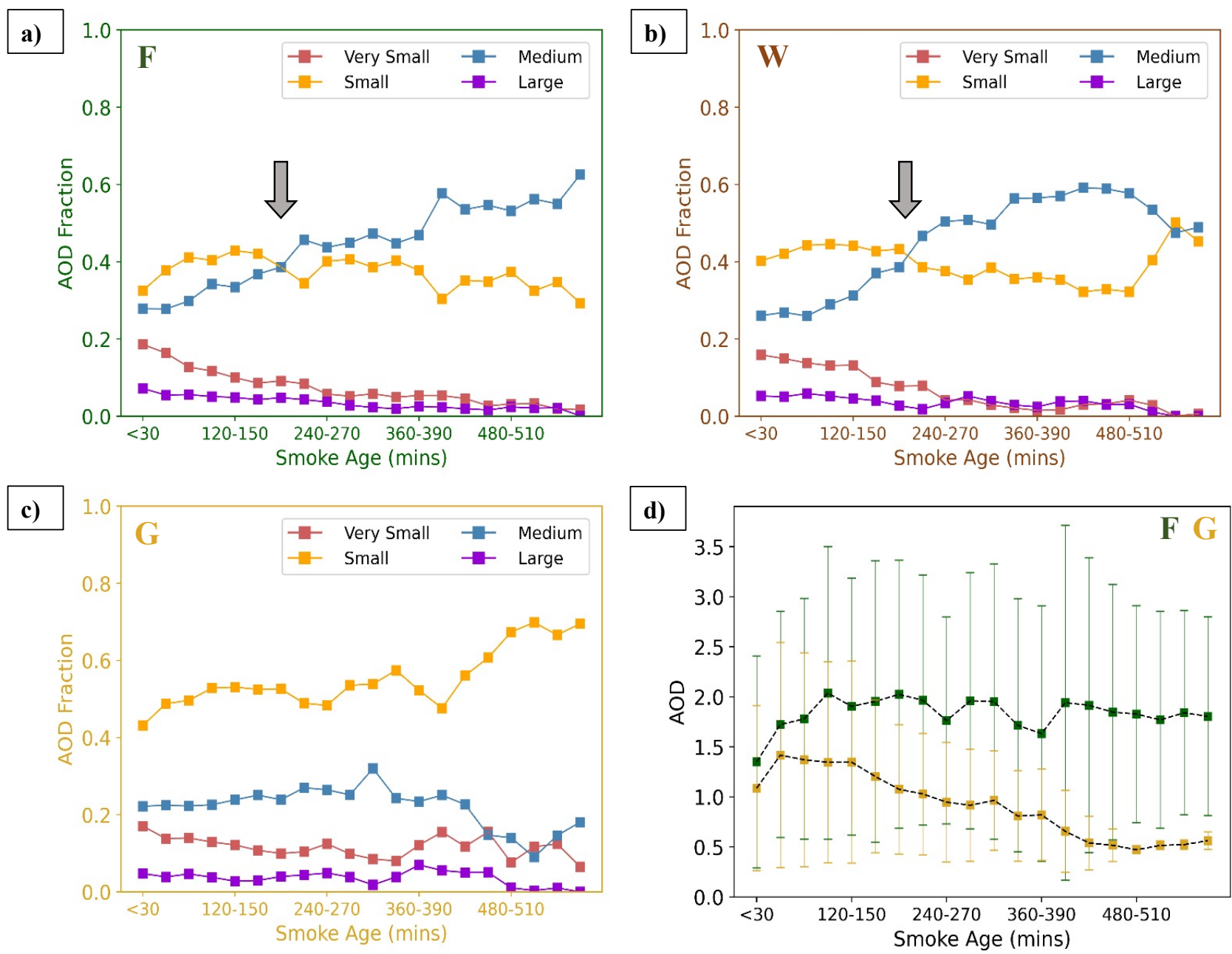

Figure 5. MISR particle-size component AOD fractions (in terms of contribution to the total AOD, from 0 to 1 ) by smoke age for (a) Forest plumes, (b) Woody plumes, and (c) Grassy plumes. In (d), the MISR mid-visible AOD is plotted by age for Forest and Grassy plumes, for reference. The points represent the mean values, and the whiskers are standard deviations. Arrows help highlight the points of important particle-size transitions. 

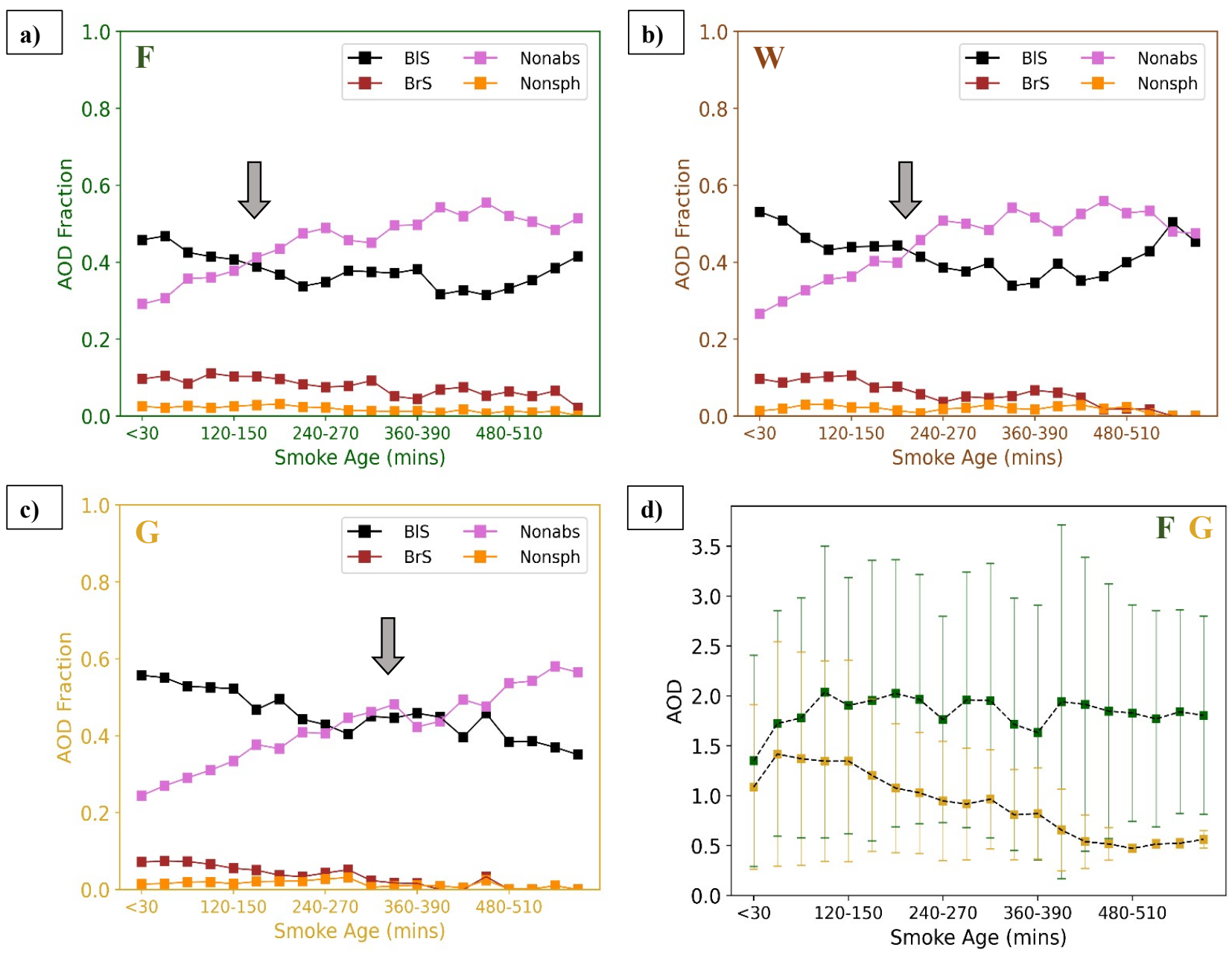

525 Figure 6. MISR particle-type component AOD fractions (in terms of contribution to the total AOD, from 0 to 1 ) by smoke age for (a) Forest plumes, (b) Woody plumes, and (c) Grassy plumes. In (d), the MISR mid-visible AOD is plotted by age for Forest and Grassy plumes, for reference. The points represent the mean values, and the whiskers are standard deviations. Arrows help highlight the point of important particle-size transitions.

\subsection{Downwind Particle Evolution and Differences Between Fire Types}

To understand how particle properties change with smoke age both within and between plumes, we use MINX wind speeds and distance from the fire source to divide each plume into discrete age bins at approximately 30-minute intervals, where possible. In $6 \%$ of cases, poor retrieval quality and/or gaps in the retrieved plume area prevented us from calculating age in a plume.

Overall, REPS increases (lower ANG) whereas REPA decreases (higher SSA) with age. This is generally consistent

535 with literature on the typical aerosol aging processes in BB plumes, as particles oxidize and hydrate, and gaseous pre-cursors such as volatile organics condense onto their surface to increase particle size; these processes often lead to reduced lightabsorption, especially in the case of BIS. As coatings generally increase hygroscopicity, this can contribute to increased 
particle hydration, size and SSA, especially as the plume cools, which increases the effective RH. However, we find that plumes in the G category exhibit decreased REPS with age, unlike the trends seen in F and W plumes (Figure 4a-c). This is accompanied by a dramatic decrease in the downwind plume AOD not seen in F or W plumes (Figure 4d). In Figure 5, trends in REPS are further illustrated via the downwind evolution in the AOD fractions of the four particle-size components. In particular, the partitioning between AOD fractions of small and medium particles is highlighted. We observe a transition from small-dominated to medium-dominated smoke at approximately the 3-hour mark in both $\mathrm{F}$ and $\mathrm{W}$ plumes, whereas $\mathrm{G}$ plumes never experience this transition and in fact tend to show the opposite. In the context of the total plume AOD decreasing, this may indicate that dilution with background air is more important in G plumes compared to $\mathrm{F}$ and $\mathrm{W}$ plumes. In contrast, $\mathrm{F}$ and $\mathrm{W}$ plumes appear to experience downwind particle growth due to a dominance of condensation/hydration. The decreased AOD and particle size may also indicate that G plumes experience a stronger shift in gas-particle partitioning downwind, as the mixing of cleaner background air into the plume shifts the equilibrium for semi-volatile compounds from the particle phase to the gas phase, resulting in stronger rates of evaporation at lower concentrations [Garafolo et al., 2019].

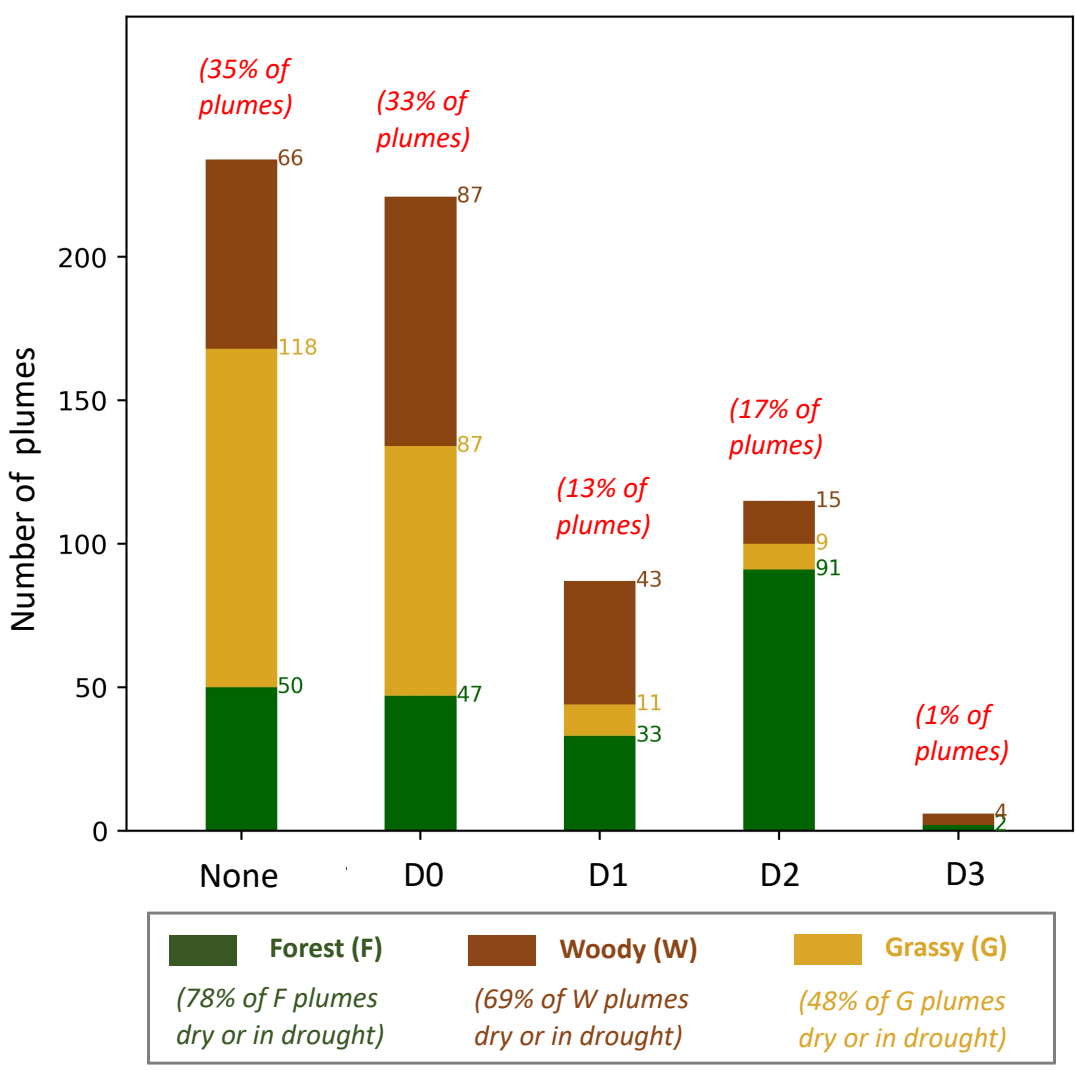

None - Normal or wetter than normal
D0 - Abnormally dry
D1 - Moderate drought
D2 - Severe Drought
D3 - Extreme Drought

Figure 7. The number of plumes observed in each drought category (see key), colored by plume type. 

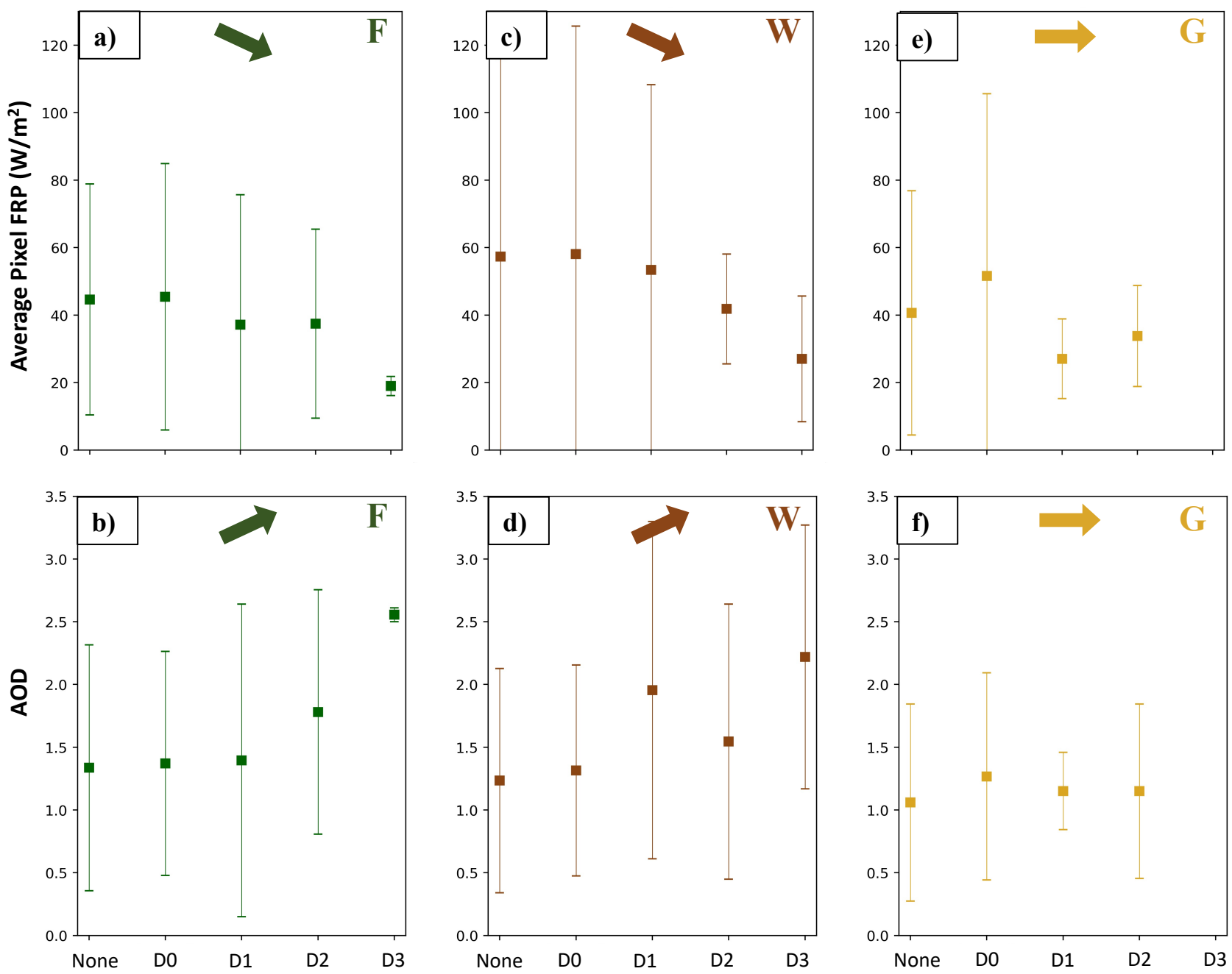

555 Figure 8. Median plume FRP (top row) according to plume type and drought level; Median plume AOD (bottom row) according to plume type and drought level. Panels are color-coded by plume type and identified with the appropriate abbreviation in the top right corner. Points represent the mean values, and whiskers are the standard deviations. Arrows highlight the general trends with increasing drought.

Although plume REPA decreases downwind in all three plume types, the timescales over which the particle-type components transition from absorbing-dominated to non-absorbing-dominated are significantly different between $\mathrm{G}$ plumes and the other two plume types. Non-absorbing particles begin to dominate over the B1S components at approximately the 3hour mark in $\mathrm{F}$ and $\mathrm{W}$ plumes, whereas the transition takes between $\sim 4$ and $\sim 7$ hours in G plumes. The longer retrieved lifetime for BIS in G plumes may indicate reduced levels of oxidation, which is consistent with the fact that flaming fires emit less VOCs that are important in modulating gas-phase oxidation chemistry [Liu et al., 2017; Koppmann et al., 2005; Donahue et al., 2014]. This would also help account for smaller particle sizes in G plumes, as VOC condensation is an important mechanism for particle growth. 

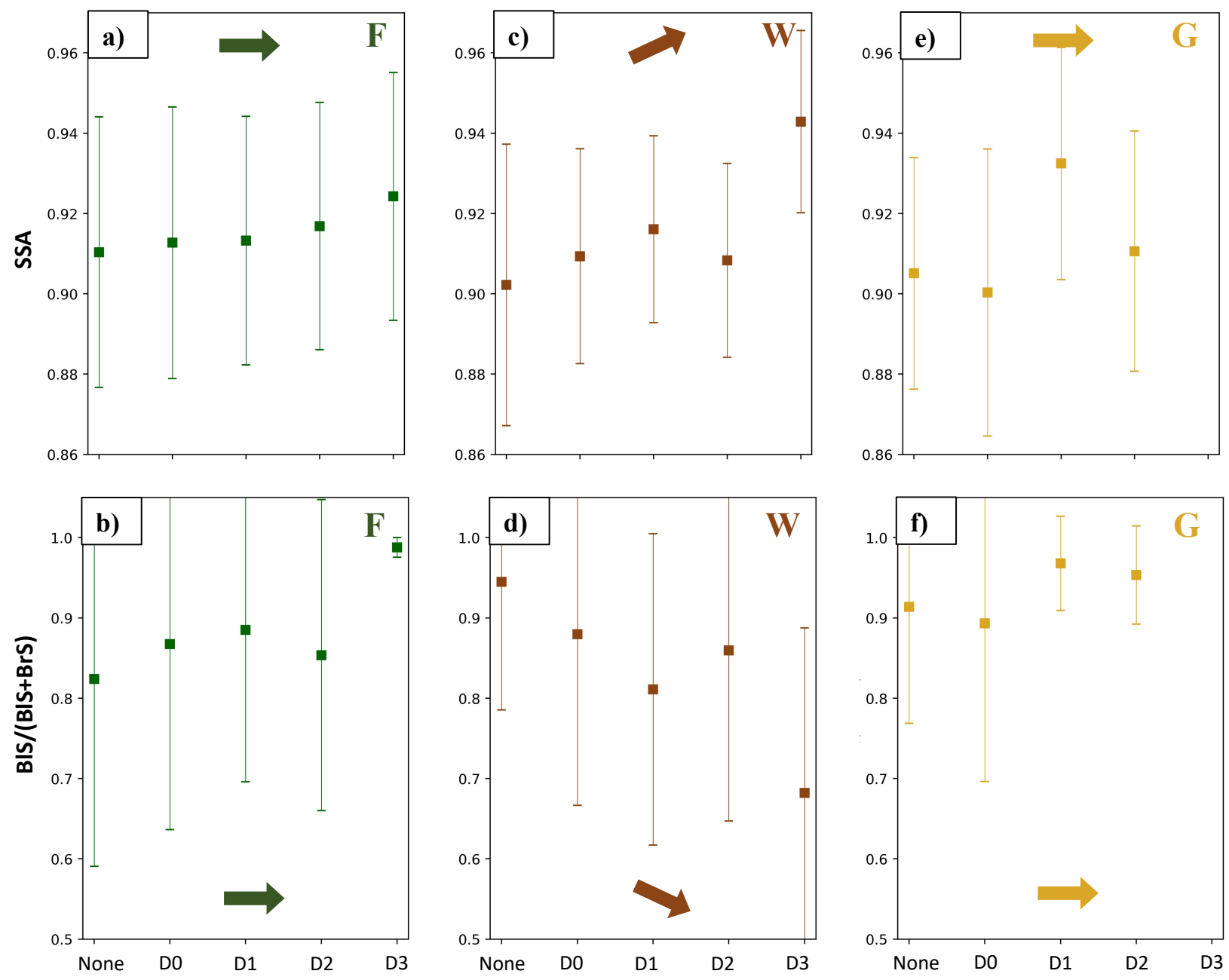

Figure 9. MISR mid-visible single scattering albedo (top row) and the fraction of AOD from BlS vs. the sum of both BlS and BrS (bottom row) for different drought conditions. Decreasing values indicate lower amounts of BrS and higher amounts of BlS. Panels are color-coded by plume type and identified with the appropriate abbreviation in the top right corner. Points represent the mean, and whiskers are the standard deviations. Arrows help highlight the general trends with increasing drought index.

\subsection{Impact of Drought on Particle Properties}

The majority of plumes (65\%) burned during drought or abnormally dry conditions, with $\mathrm{F}$ and $\mathrm{W}$ plumes tending

575 to respond to drought more than G plumes overall (Figure 7). Overall, AOD increases whereas median FRP decreases with increasing drought severity in both $\mathrm{F}$ and $\mathrm{W}$ plumes, suggesting a change in the fraction of smoldering to flaming regimes in these biomes. In addition, increased tree cover (conceivably from a shift in the relative fraction of tree-dense areas contributing to the burn) and higher smoke opacity may act to obscure the 4-micron radiance signatures detected by MODIS, 
contributing lower observed pixel FRP. In contrast, G plumes experience no change in AOD or FRP with increasing drought

(Figure 8). These differences are consistent with other studies on fuel consumption across different biomes - areas with low tree-cover density (e.g., grasslands) experience lower tree mortality rates during drought stress compared to areas with high tree-cover density [van der Werf et al., 2010]. We therefore expect forested areas to experience larger swings in the amount of fuel available for burning based on drought, compared to low-biomass-density areas. The considerable increases in fuel availability translate to larger, more intense fires in the $\mathrm{F}$ and $\mathrm{W}$ categories. In fact, the cumulative FRP over the burning area increases with drought in $\mathrm{F}$ and $\mathrm{W}$ fires, corresponding to a larger number of fire detections per plume.

We find that increasing drought index in $\mathrm{W}$ plumes is generally correlated with decreasing particle light-absorption and $\mathrm{BrS}$ fractions, trends that are not present in $\mathrm{F}$ and $\mathrm{G}$ plumes (Figure 9). This may indicate that the aforementioned shifts in fuel type and burning regimes are more pronounced in $\mathrm{W}$ plumes. A possible explanation is that fires identified as $\mathrm{W}$ plumes experience some of the largest swings in the types of fuels available for burning, as they contain a more even mixture of grassy vs. woody vegetation based on our definitions. As drought persists, the relative increase in the amount of woody fuels available to burn in $\mathrm{W}$ fires outpaces that in F fires, which consume a larger fraction of woody fuels to begin with, as per our fire type definitions. Similarly, the absence of coarse woody fuels in grassy biomes would prevent any significant shift in fuel types.

\section{Conclusions}

This work, focused on Canada and Alaska, represents the first regional study in an ongoing effort to characterize wildfire particles across the globe. Thanks to extensive validation experiments in previous work, we here apply our knowledge about the relationships between particle chemistry/microphysics and the TOA optical signatures obtained by MISR to create a regional inventory of particle type (black smoke vs. brown smoke vs. soil/dust vs. non-light-absorbing particles), inferred trends in particle evolution (e.g., oxidation, size-selective dilution, hydration/condensation, etc.), and the modulating forces behind these, such as meteorology, land cover type, and fire intensity. The MISR plume heights and particle properties exhibit patterns that match well the existing literature on the role of burning conditions and vegetation in wildfire smoke properties. Furthermore, the combination of MISR observations with other satellite and modeling datasets allow us to infer the dominant factors driving particle properties and their evolution under different conditions. This represents new territory in BB aerosol studies.

Specifically, we find distinct patterns in plume properties when the data are partitioned into three categories based on the relative fractions of forest (F), woody savanna (W), and grasslands/savannas/shrublands (G). The largest differences are typically found between $\mathrm{F}$ and $\mathrm{G}$ fires, as these represent the extremes in fuel type for fires in the study region. The most statistically significant differences are observed in: 1) MISR AOD, with thicker plumes in the F category; and 2) particle size and light-absorption, with F plumes exhibiting both larger and less absorbing particles than G plumes. These differences are 
610 likely driven at least partially by the relative fractions of flaming and smoldering fire in each category, as smoldering is more dominant in $\mathrm{F}$ fires.

There also appear to be distinct differences in how smoke particles age downwind with plume type, and the timescales over which these changes occur. In G plumes, particles are not observed to experience increases in particle size, it takes comparatively longer for the BIS AOD fraction to diminish, and total AOD drops significantly downwind. In F and W

615 plumes, the near-source dominance of small particles transitions toward medium particles, non-absorbing particles begin to dominate over BIS particles much sooner, and total AOD is relatively consistent downwind. Based on these trends, we infer that $\mathrm{G}$ plumes and $\mathrm{F} / \mathrm{W}$ plumes experience varying types and degrees of atmospheric aging. Namely, we infer that:

1) G plumes experience less oxidation and condensation compared to $F$ and $W$ plumes, evidenced by the higher overall absorbing aerosol fraction retrieved by MISR and the fact that flaming fires produce fewer VOC emissions

2) Dilution may play a larger role in particle size for G plumes, supported by decreasing particle sizes downwind and reduced AOD downwind

These conclusions represent new territory, as to-date there have been no other large-scale regional studies relating particle properties to specific aging mechanisms and the timescales over which they occur.

We also find that drought plays a role in AOD for both $\mathrm{F}$ and $\mathrm{W}$ fires, but that only $\mathrm{W}$ fires appear to respond significantly to drought in terms of the smoke particle properties. G fires are resistant to changes from drought, which is consistent with current expectation.

Future work will involve applying the MISR RA to plumes across a wide variety of other biomes and climate conditions. Based on current knowledge of the differences in fire properties between regions, we expect to find significant differences in particle properties, plume heights, and other retrieved or modeled quantities, with implications for the underlying mechanisms and the timescales over which they operate. Such observational constraints on BB particle-type distributions and aging regimes could greatly benefit regional and global climate and air quality modeling efforts.

Competing Interests: The authors declare the following competing interests: $\mathrm{Z}$. Li is a member of the ACP editorial board.

Code/Data Availability: The MISR Research Aerosol (RA) algorithm is a proprietary product. MINX is available for public use. The RA and MINX results for individual plumes can be found at the NASA Langley Atmospheric Data Center (ASDC) Distributed Active Archive Center (DAAC): [final address is TBD].

640 Author Contributions: The project was first conceptualized by R.K, and the development and design of the methodology were a collaboration between R.K. and K.J.N. The RA algorithm used in this project was developed by R.K. and J.L., and is maintained by J.L. K.J.N. developed the tools used to process, analyze, and visualize all data. Formal analysis of the results 
was conducted by K.J.N and R.K., who together wrote the original draft. Z.L. reviewed and provided comments on the manuscript. All authors read and agreed to the final version of the manuscript.

Funding: The work of K.T. Junghenn Noyes is currently supported by the NASA Postdoctoral Program (NPP), managed by the Universities Space Research Administration (USRA). Part of this work was conducted during K.T. Junghenn Noyes' $\mathrm{Ph}$.D. studies, which was supported by a grant from the Maryland Space Grant Consortium under Richard C. Henry and Matt Collinge, as well as NASA's Atmospheric Composition Modeling and Analysis Program under Richard Eckman through a grant to R. Kahn, and a NASA grant (NNX16AN61G) that supports Z. Li. The work of R.A. Kahn and J.A. Limbacher is supported in part by NASA's Climate and Radiation Research and Analysis Program under Hal Maring, NASA's Atmospheric Composition Modeling and Analysis Program under Richard Eckman, and the EOS Terra and MISR Projects.

Acknowledgements: The authors thank Steven F. Noyes for his assistance with the development of the software tools used for data processing and analysis.

\section{References}

Agriculture and Agri-food Canada. ISO 19131 Canadian Drought Monitor - Data Product Specifications. Available Online: https://www.agr.gc.ca/atlas/supportdocument_documentdesupport/canadianDroughtMonitor/en/ISO_19131_Canadian_Drou ght_Monitor_Data_Product_Specification.pdf.

Ahern, A.T., Robinson, E.S., Tkacik, D.S., Saleh, R., Hatch, L.E., Barsanti, K.C., Stockwell, C.E., Yokelson, R.J., Presto, A.A., Robinson, A.L., et al.: Production of secondary organic aerosol during aging of biomass burning smoke from fresh fuels and its relationship to VOC precursors, J. Geophys. Res. Atmos., 124, 3583-3606, doi: 10.1029/2018JD029068, 2019

665 Akagi, S.K., Craven, J.S., Taylor, J.W., McMeeking, G.R., Yokelson, R.J., Burling, I.R., Urbanski, S.P., Wold, C.E., Seinfeld, J.H., Coe, H., et al.: Evolution of Trace Gases and Particles Emitted by a Chaparral Fire in California, Atmos. Chem. Phys. 12, 1397-1421, doi: 10.5194/acp-12-1397-2012, 2012.

Akagi, S. K., Yokelson, R. J., Wiedinmyer, C., Alvarado, M. J., Reid, J. S., Karl, T., Crounse, J. D., and Wennberg, P. O.:

670 Emission factors for open and domestic biomass burning for use in atmospheric models, Atmos. Chem. Phys., 11, 40394072, doi: 10.5194/acp-11-4039-2011, 2011.

Albrecht, B.A.: Aerosols, Cloud Microphysics, and Fractional Cloudiness, Science, 245, 1227-1230, doi: 10.1126/science.245.4923.1227, 1989.

Andreae, M.O. and Gelencser, A.: Black Carbon or Brown Carbon? The Nature of Light-Absorbing Carbonaceous Aerosols, Atmos. Chem. Phys., 18, 3419-3463, doi: 10.5194/acp-6-3131-2006, 2006.

Bertschi, I., Yokelson, R.J., Ward, D.E., Babbitt, R.E., Susott, R.A., Goode, J. G., and Hao, W.M.: Trace gas and particle 680 emissions from fires in large diameter and belowground biomass fuels, J. Geophys. Res., 108, 8472, doi:10.1029/2002JD002100, 2003. 
Bond, T.C., Doherty, S.J., Fahey, D.W., Forster, P.M., Berntsen, T., DeAngelo, B.J., Flanner, M.G., Ghan, S., Kaercher, B., Koch, D., et al.: Bounding the role of black carbon in the climate system: A scientific assessment, J. Geophys. Res. Atmos., 118, 5380-5552, doi: 10.1002/jgrd.50171, 2013.

Bosilovich, M., Lucchesi, R., and Suarez, M. MERRA-2: File specification. Available online: https://gmao.gsfc.nasa.gov/pubs/docs/Bosilovich785.pdf. (Accessed on 20 March 2021). 2016.

690 Chakrabarty, R.K., Gyawali, M., Yatavelli, R.L.N., Pandey, A., Watts, A.C., Knue, J., Chen, L.-W.A., Pattison, R.R., Tsibart, A., Samburova, V., et al.: Brown Carbon Aerosols from Burning of Boreal Peatlands: Microphysical Properties, Emission Factors, and Implications for Direct Radiative Forcing, Atmos. Chem. Phys., 16, 3033-3040, doi: 10.5194/acp-163033-2016, 2016.

695 Chakrabarty, R.K., Moosmüller, H., Chen, L.-W.A., Lewis, K., Arnott, W.P., Mazzoleni, C., Dubey, M.K., Wold, C.E., Hao, W.M., and Kreidenweis, S.M.: Brown Carbon in Tar Balls from Smoldering Biomass Combustion, Atmos. Chem. Phys., 10, 6363-6370, doi: 10.5194/acp-10-6363-2010, 2010.

Chen, W.-T., Kahn, R.A., Nelson, D., Yau, K., and Seinfeld, J.H.: Sensitivity of Multiangle Imaging to the Optical and Microphysical Properties of Biomass Burning Aerosols, J. Geophys. Res., 113, D10203, doi:10.1029/2007JD009414, 2008.

Colarco, P.R., Schoeberl, M.R., Doddridge, B.G., Marufu, L.T., Torres, O., and Welton, E.J.: Transport of Smoke from Canadian Forest Fires to the Surface near Washington, D.C.: Injection Height, Entrainment, and Optical Properties, J. Geophys. Res., 109, doi: 10.1029/2003JD004248, 2004.

Dalirian, M., Ylisirniö, A., Buchholz, A., Schlesinger, D., Ström, J., Virtanen, A., and Riipinen, I.: Cloud droplet activation of black carbon particles coated with organic compounds of varying solubility, Atmos. Chem. Phys., 18, 12477-12489, doi:10.5194/acp-18-12477-2018, 2018.

710 Damoah, R., Spichtinger, N., Forster, C., James, P., Mattis, I., Wandinger, U., Beirle, S., Wagner, T., and Stohl, A.: Around the world in 17 days - hemispheric-scale transport of forest fire smoke from Russia in May 2003, Atmos. Chem. Phys., 4, 1311-1321, doi: 10.5194/acp-4-1311-2004, 2004.

Diner, D.J., Beckert, J.C., Reilly, T.H., Bruegge, C.J., Conel, J.E., Kahn, R.A., Martonchik, J.V., Ackerman, T.P., Davies, 715 R., Gerstl, S.A.W., et al.: Multi-Angle Imaging SpectroRadiometer (MISR) Instrument Description and Experiment Overview, IEEE Trans., 36, 1072-1087, doi: 10.1109/36.700992, 1998.

Donahue, N.M., Robinson, A.L., Trump, E.R., Riipinen, I., and Kroll, J.H.: Volatility and aging of atmospheric organic aerosol, Top Curr Chem., 339, 97-143, doi: 10.1007/128_2012_355, 2014.

Dubovik, O., Holben, B., Eck, T.F., Smirnov, A., Kaufman, Y.J., King, M.D., Tanre, D., and Slutsker, I.: Variability of Absorption and Optical Properties of Key Aerosol Types Observed in Worldwide Locations, J. Atmos. Sci., 59, 19, doi: 10.1175/1520-0469(2002)059<0590:VOAAOP>2.0.CO;2, 2002.

725 Eck, T.F., Holben, B.N., Reid, J.S., O’Neill, N.T., Schafer, J.S., Dubovik, O., Smirnov, A., Yamasoe, M.A., and Artaxo, P.: High Aerosol Optical Depth Biomass Burning Events: A Comparison of Optical Properties for Different Source Regions, Geophys. Res. Lett., 30, doi: 10.1029/2003GL017861, 2003.

Feng, Y., Ramanathan, V., and Kotamarthi, V.R.: Brown Carbon: A Significant Atmospheric Absorber of Solar Radiation?,

Atmos. Chem. Phys., 13, 8607-8621, doi: 10.5194/acp-13-8607-2013, 2013. 
Flower, V.J.B. and Kahn, R.A.: Assessing the Altitude and Dispersion of Volcanic Plumes Using MISR Multi-Angle Imaging from Space: Sixteen Years of Volcanic Activity in the Kamchatka Peninsula, Russia, J. Volcanal. Geoth. Res., 337, 1-15, doi: 0.1016/j.jvolgeores.2017.03.010, 2017a.

Flower, V.J.B. and Kahn, R.A.: Distinguishing Remobilized Ash From Erupted Volcanic Plumes Using Space-Borne Multiangle Imaging: Remobilized Ash Plumes, Geophys. Res. Lett., 44, 10772-10779, doi: 10.1002/2017GL074740, $2017 \mathrm{~b}$.

Flower, V.J.B. and Kahn, R.A.: Karymsky Volcano Eruptive Plume Properties Based on MISR Multi-Angle Imagery and the

Volcanological Implications, Atmos. Chem. Phys., 18, 3903-3918, doi: 10.5194/acp-18-3903-2018, 2018.

Flower, V.J.B. and Kahn, R.A.: Interpreting the Volcanological Processes of Kamchatka, Based on Multi-Sensor Satellite Observations, Remote Sens. Environ., 237, 111585, doi: 10.1016/j.rse.2019.111585, 2020a.

745 Flower, V.J.B. and Kahn, R.A.: The evolution of Icelandic volcano emissions, as observed from space in the era of NASA's Earth Observing System (EOS), J. Geophys. Res. Atmos., 125, e2019JD031625, doi: 10.1029/2019JD031625, $2020 \mathrm{~b}$.

Friedl, M. and Sulla-Menashe, D.: MCD12Q1 MODIS/Terra+Aqua Land Cover Type Yearly L3 Global 500m SIN Grid V006 [Data set]. NASA EOSDIS Land Processes DAAC. doi: 10.5067/MODIS/MCD12Q1.006, 2019.

Gelaro, R., McCarty, W., Suárez, M. J., Todling, R., Molod, A., Takacs, L., Randles, C. A., Darmenov, A., Bosilovich, M.G., Reichle, R., Wargan, K., Coy, L., Cullather, R., et al.: The Modern-Era Retrospective Analysis for Research and Applications, Version 2 (MERRA-2), J. of Climate, 30(14), 5419-5454, doi: 10.1175/JCLI-D-16-0758.1, 2017.

755 Giglio, L., Descloitres, J., Justice, C. O., and Kaufman, Y. J.: An enhanced contextual fire detection algorithm for MODIS, Remote Sens. Environ., 87, 273-282, doi: 10.1016/S0034-4257(03)00184-6, 2003.

Giglio, L. and Justice, C.: MOD14 MODIS/Terra Thermal Anomalies/Fire 5-Min L2 Swath 1km V006 [Data set]. NASA EOSDIS Land Processes DAAC., doi: 10.5067/MODIS/MOD14.006, 2015.

Gonzalez-Alonso, L., Val Martin, M., and Kahn, R.A.: Biomass burning smoke heights over the Amazon observed from the space, Atmos. Chem. Phys., 19, 1685-1702, doi:10.5194/acp-19-1685-2019, 2019.

Hansen, J., Sato, M., and Ruedy, R.: Radiative forcing and climate response, J. Geophys. Res., 102, doi: 10.1029/96JD03436, 1997.

Heim, R.R., Jr.: A Review of Twentieth-Century Drought Indices Used in the United States, Bulletin of the American Meteorological Society, 83(8), 1149-1166, doi: 10.1175/1520-0477-83.8.1149, 2002.

770 Hennigan, C.J., Westervelt, D.M., Riipinen, I., Engelhart, G.J., Lee, T., Collett, J.L., Pandis, S.N., Adams, P.J., and Robinson, A.L.: New particle formation and growth in biomass burning plumes: An important source of cloud condensation nuclei, Geophys. Res. Lett., 39, L09805, doi: 10.1029/2012GL050930, 2012.

Hobbs, P.V. and Radke, L.F.: Cloud Condensation Nuclei from a Simulated Forest Fire, Science, 163, 279-280, doi: 10.1126/science.163.3864.279, 1969.

Junghenn Noyes, K., Kahn, R., Sedlacek, A., Kleinman, L., Limbacher, J., and Li, Z.: Wildfire Smoke Particle Properties and Evolution, from Space-Based Multi-Angle Imagin,. Remote Sens., 12, 769, doi: 10.3390/rs12050769, 2020a.

780 Junghenn Noyes, K., Kahn, R.A., Limbacher, J.A., Li, Z., Fenn, M.A., Giles, D.M., Hair, J.W., Katich, J.M., Moore, R.H., Robinson, C.E., Sanchez, K.J., Shingler, T.J., Thornhill, K.L., Wiggins, E.B., and Winstead, E.L.: Wildfire Smoke Particle 
Properties and Evolution, From Space-Based Multi-Angle Imaging II: The Williams Flats Fire during the FIREX-AQ Campaign, Remote Sens., 12, 3823, doi: 10.3390/rs12223823, 2020 b.

Kahn, R.A.: A global perspective on wildfires, EOS Am. Geophys. Union, 101, doi: 10.1029/2020EO138260, 2020.

Kahn, R.A., Banerjee, P., and McDonald, D.: Sensitivity of multiangle imaging to natural mixtures of aerosols over ocean, J. Geophys. Res., 106( D16), 18219- 18238, doi: 10.1029/2000JD900497, 2001.

Kahn, R.A., Chen, Y., Nelson, D.L., Leung, F.-Y., Li, Q., Diner, D.J., and Logan, J.A.: Wildfire Smoke Injection Heights: Two Perspectives from Space, Geophys. Res. Lett., 35, L04809, doi: 10.1029/2007GL032165, 2008.

Kahn, R.A. and Gaitley, B.J.: An Analysis of Global Aerosol Type as Retrieved by MISR: MISR Aerosol Type. J. Geophys. Res. Atmos., 120, 4248-4281, doi: 10.1002/2015JD023322, 2015.

Kahn, R.A., Gaitley, B.J., Garay, M.J., Diner, D.J., Eck, T., Smirnov, A., and Holben, B.N.: Multiangle Imaging SpectroRadiometer global aerosol product assessment by comparison with the Aerosol Robotic Network, J. Geophys. Res., 115, D23209, doi: 10.1029/2010JD014601, 2010.

800 Kahn, R.A. and Limbacher, J.: Eyjafjallajökull Volcano Plume Particle-Type Characterization from Space-Based MultiAngle Imaging, Atmos. Chem. Phys., 12, 9459-9477, doi: 10.5194/acp-12-9459-2012, 2012.

Kaufman, Y.J. and Fraser, R.S.: The Effect of Smoke Particles on Clouds and Climate Forcing, Science, 277, 1636-1639, doi: http://doi.org/10.1126/science.277.5332.1636, 1997.

Kirchstetter, T.W., Novakov, T., and Hobbs, P.V.: Evidence that the spectral dependence of light absorption by aerosols is affected by organic carbon, J. Geophys. Res. Atmos., 109, D21208, doi: 10.1029/2004JD004999, 2004.

Koch, D. and Del Genio, A.D.: Black carbon semi-direct effects on cloud cover: Review and synthesis, Atmos. Chem. Phys. 2010, 10, 7685-7696, doi: 10.5194/acp-10-7685-2010.

Koppmann, R., von Czapiewski, K., and Reid, J.S.: A review of biomass burning emissions, part I: gaseous emissions of carbon monoxide, methane, volatile organic compounds, and nitrogen containing compounds, Atmos. Chem. Phys. Discuss., 5 (5), 10455-10516, doi: 10.5194/acpd-5-10455-2005, 2005.

Lee, J., Hsu, N.C., Sayer, A.M., Bettenhausen, C., and Yang, P.: AERONET-Based Nonspherical Dust Optical Models and Effects on the VIIRS Deep Blue/SOAR Over Water Aerosol Product, J. Geophys. Res. Atmos., 122, 10384-10401. DOI: 10.1002/2017JD027258, 2017.

820 Lawrimore, J., Heim Jr., R.R., Svoboda, M., Swail, V., and Englehart, P.J.: Beginning a new era of drought monitoring across North America, Bulletin of the American Meteorological Society, 83, 1191-1192, doi: 10.1175/1520-0477-83.8.1191, 2002.

Limbacher, J.A. and Kahn, R.A.: MISR Research-Aerosol-Algorithm Refinements for Dark Water Retrievals, Atmos. Meas.

Technol., 7, 3989-4007, doi: 10.5194/amt-7-3989-2014, 2014.

Limbacher, J.A. and Kahn, R.A.: Updated MISR Over-Water Research Aerosol Retrieval Algorithm-Part 2: A Multi-Angle Aerosol Retrieval Algorithm for Shallow, Turbid, Oligotrophic, and Eutrophic Waters, Atmos. Meas. Technol., 12, 675-689, doi: 10.5194/amt-12-675-2019, 2019. 
Liu, X., Huey, G., Yokelson, R.J., Selimovic, V., Simpson, I.J., Müller, M., Jimenez, J.L., et al.: Airborne measurements of western U.S. wildfire emissions: Comparison with prescribed burning and air quality implications, J. Geophys. Res. Atmos., 122, 6108- 6129, doi:10.1002/2016JD026315, 2017.

835 Liu,Y., Goodrick, S., and Heilman, W.: Wildland fire emissions, carbon, and climate: Wildfire-climate interactions, Forest Ecol. Manag., 317, 80-96, doi: 10.1016/j.foreco.2013.02.020, 2014.

Lyapustin, A. and Wang, Y.: MODIS Multi-Angle Implementation of Atmospheric Correction (MAIAC) Data User's Guide. NASA: Greenbelt, MD, USA. Available online: https://modis-land.gsfc.nasa.gov/pdf/MCD19_UserGuide_final_Feb-62018.pdf. (Accessed 20 June 2019), 2018.

Nelson, D.L., Chen, Y., Kahn, R.A., Diner, D.J., and Mazzoni, D.: Example Applications of the MISR INteractive EXplorer (MINX) Software Tool to Wildfire Smoke Plume Analyses, Remote Sens. Fire Sci. Appl., 708909, doi: 10.1117/12.795087, 2008.

Nelson, D., Garay, M., Kahn, R., Dunst, B. Stereoscopic Height and Wind Retrievals for Aerosol Plumes with the MISR INteractive EXplorer (MINX). Remote Sens., 5, 4593-4628, doi: 10.3390/rs5094593, 2013.

Nelson, D., Val, S., Kahn, R., Koeberlein, E., Tosca, M., Diner, D., and Lawshe, C.: "MISR Plume Height Project 2", MISR, NASA Jet Propulsion Laboratory, Available online: https://misr.jpl.nasa.gov/getData/accessData/MisrMinxPlumes2/.

O'Neill, N.T., Eck, T.F., Holben, B.N., Smirnov, A., Royer, A., and Li, Z.: Optical properties of boreal forest fire smoke derived from Sun photometry, J. Geophys. Res. Atmos., 107, doi:10.1029/2001JD000877, 2002.

855 Ottmar, R.O.: Smoke Management Guide for Prescribed and Wildland Fire. National Interagency Fire Center: Boise, ID, USA. Available online: https://www.nwcg.gov/sites/default/files/publications/pms420-2.pdf. (Accessed on 22 June 2020). 2001.

Ottmar, R.O., Sandberg, D.V., Riccardi, C.L., and Prichard, S.J.: An overview of the Fuel Characteristic Classification 860 System - quantifying, classifying, and creating fuelbeds for resource planning. USDA Forest Service. Available online: https://www.fs.fed.us/pnw/fera/fccs/manuscripts/ottmar_et_al_overview_final.pdf. (Accessed on 20 June 2020). 2001.

Petrenko, M., Kahn, R., Chin, M., Soja, A., Kucsera, T., and Harshvardhan.: The Use of Satellite-Measured Aerosol Optical Depth to Constrain Biomass Burning Emissions Source Strength in the Global Model GOCART, J. Geophys. Res., 117, doi:

10.1029/2012JD017870, 2012.

Reid, J.S. and Hobbs, P.V.: Physical and optical properties of young smoke from individual biomass fires in Brazil, $J$. Geophys. Res., 103, doi: 10.1029/98JD00159, 1998.

870 Reid, J.S., Koppmann, R., Eck, T.F., and Eleuterio, D.P.: A Review of Biomass Burning Emissions Part II: Intensive Physical Properties of Biomass Burning Particles, Atmos. Chem. Phys., 28, 799-825, doi: 10.5194/acp-5-799-2005, 2005.

Samset, B.H., Stjern, C.W., Andrews, E., Kahn, R.A., Myhre, G., Schulz, M., and Schuster, G.L.: Aerosol Absorption: Progress Towards Global and Regional Constraints, Curr. Clim. Chang. Rep., 4, 65-83, doi: 10.1007/s40641-018-0091-4, 2018.

Santoso, M.A., Christensen, E.G., Yang, J., and Rein, G.: Review of the Transition From Smouldering to Flaming Combustion in Wildfires, Front. Mech. Eng., 5, doi: 10.3389/fmech.2019.00049, 2019. 
Scollo, S., Kahn, R.A., Nelson, D.L., Coltelli, M., Diner, D.J., Garay, M.J., and Realmuto, V.J.: MISR Observations of Etna Volcanic Plumes, J. Geophys. Res., 117, doi: 10.1029/2011JD016625, 2012.

Scott, J.H., Burgan, R.E. Standard Fire Behavior Fuel Models: A Comprehensive Set for Use with Rothermel's Surface Fire Spread Model. Gen. Tech. Rep. RMRS-GTR-153. Fort Collins, CO: U.S. Department of Agriculture, Forest Service, Rocky 885 Mountain Research Station. Available Online: https://www.fs.fed.us/rm/pubs/rmrs_gtr153.pdf. (Accessed on 17 February 2021), 2005.

Shi, S., Cheng, T., Gu, X., Guo, H., Wu, Y., and Wang, Y.: Biomass Burning Aerosol Characteristics for Different Vegetation Types in Different Aging Periods, Environ. Int., 126, 504-511, doi: 10.1016/j.envint.2019.02.073, 2019.

Svoboda, M., LeComte, D., Hayes, M., Heim, R., Gleason, K., Angel, J., Rippey, B., Tinker, R., Palecki, M., Stooksbury, D., Miskus, D., and Stephens, S.: The Drought Monitor, Bulletin of the American Meteorological Society, 83(8), 1181-1190, doi: 10.1175/1520-0477-83.8.1181, 2002.

895 Taubman, B. F., Marufu, L. T., Vant-Hull, B. L., Piety, C. A., Doddridge, B. G., Dickerson, R. R., and Li, Z.: Smoke over haze: Aircraft observations of chemical and optical properties and the effects on heating rates and stability, J. Geophys. Res., 109, D02206, doi:10.1029/2003JD003898, 2004.

Toon, O.B., Maring, H., Dibb, J., Ferrare, R., Jacob, D.J., Jensen, E.J., Luo, Z.J., Mace, G.G., Pan, L.L., Pfister, L., et al.:

900 Planning, Implementation, and Scientific Goals of the Studies of Emissions and Atmospheric Composition, Clouds and Climate Coupling by Regional Surveys (SEAC4RS) Field Mission, J. Geophys. Res. Atmos., 121, 4967-5009, doi: 10.1002/2015Jd024297, 2016.

Tosca, M.G., Randerson, J.T., Zender, C.S., Nelson, D.L., Diner, D.J., Logan, J.A. Dynamics of Fire Plumes and Smoke Clouds Associated with Peat and Deforestation Fires in Indonesia. J. Geophys. Res., 116, D08207, doi: 10.1029/2010JD015148, 2011.

Urbanski, S.P.: Combustion efficiency and emission factors for wildfire-season fires in mixed conifer forests of the northern Rocky Mountains, US, Atmos. Chem. Phys., 13, 7241-7262, doi: 10.5194/acp-13-7241-2013, 2013.

Val Martin, M., Kahn, R., and Tosca, M.: A Global Analysis of Wildfire Smoke Injection Heights Derived from SpaceBased Multi-Angle Imaging, Remote Sens., 10, 1609, doi: 10.3390/rs10101609, 2018.

Val Martin, M., Logan, J.A., and Kahn, R.A.: Smoke Injection Heights from Fires in North America: Analysis of 5 Years of 915 Satellite Observations, Atmos. Chem. Phys., 10, 1491-1510, doi: 10.5194/acp-10-1491-2010, 2010.

van der Werf, G. R., Randerson, J. T., Giglio, L., Collatz, G. J., Mu, M., Kasibhatla, P. S., Morton, D. C., DeFries, R. S., Jin, Y., and van Leeuwen, T. T.: Global fire emissions and the contribution of deforestation, savanna, forest, agricultural, and peat fires (1997-2009), Atmos. Chem. Phys., 10, 11707-11735, doi: 10.5194/acp-10-11707-2010, 2010.

Vant-Hull, B., Li, Z., Taubman, B. F., Levy, R., Marufu, L., Chang, F.-L., Doddridge, B. G., and Dickerson, R. R.: Smoke over haze: Comparative analysis of satellite, surface radiometer, and airborne in situ measurements of aerosol optical properties and radiative forcing over the eastern United States, J. Geophys. Res., 110, D10S21, DOI: 10.1029/2004JD004518, 2005.

Vernon, C.J., Bolt, R., Canty, T., and Kahn, R.A.: The Impact of MISR-Derived Injection Height Initialization on Wildfire and Volcanic Plume Dispersion in the HYSPLIT Model, Atmos. Meas. Technol., 11, 6289-6307, doi: 10.5194/amt-11-62892018, 2018. 
930 Wang, Z.B., Hu, M., Yue, D.L., He, L.Y., Huang, X.F., Yang, Q., Zheng, J., Zhang, R.Y., and Zhang, Y.H.: New particle formation in the presence of a strong biomass burning episode at a downwind rural site in PRD, China, Tellus B, 65:1, 19965, doi: 10.3402/tellusb.v65i0.19965, 2013.

Warner, J. and Twomey, S.: The Production of Cloud Nuclei by Cane Fires and the Effect on Cloud Droplet Concentration, 935 J. Atmos. Sci., 24, 704-706, doi: 10.1175/1520-0469(1967)024<0704:TPOCNB>2.0.CO;2, 1967.

Wiggins, E. B., Andrews, A., Sweeney, C., Miller, J. B., Miller, C. E., Veraverbeke, S., Commane, R., Wofsy, S., Henderson, J. M., and Randerson, J. T.: Boreal forest fire CO and CH4 emission factors derived from tower observations in Alaska during the extreme fire season of 2015, Atmos. Chem. Phys., 21, 8557-8574, doi: 10.5194/acp-21-8557-2021, 2021.

Yokelson, R.J., Crounse, J.D., DeCarlo, P.F., Karl, T., Urbanski, S., Atlas, E., Campos, T., Shinozuka, Y., Kapustin, V., Clarke, A.D., et al.: Emissions from Biomass Burning in the Yucatan, Atmos. Chem. Phys., 28, 5785, doi: 10.5194/acp-95785-2009, 2009.

945 Yokelson, R. J., Susott, R., Ward, D. E., Reardon, J., and Griffith, D. W. T.: Emissions from smoldering combustion of biomass measured by open-path Fourier transform infrared spectroscopy, J. Geophys. Res, 102( D15), 18865-18877, doi:10.1029/97JD00852, 1997.

Yu, Y., Kalashnikova, O.V., Garay, M.J., Lee, H., and Notaro, M.: Identification and Characterization of Dust Source 950 Regions Across North Africa and the Middle East Using MISR Satellite Observations, Geophys. Res. Lett., 45, 6690-6701, doi: 10.1029/2018GL078324, 2018.

Zhou, S., Collier, S., Jaffe, D.A., Briggs, N.L., Hee, J., Sedlacek, A.J., III, Kleinman, L., Onasch, T.B., and Zhang, Q.: Regional Influence of Wildfires on Aerosol Chemistry in the Western US and Insights into Atmospheric Aging of Biomass Burning Organic Aerosol, Atmos. Chem. Phys., 17, 2477-2493, doi: 10.5194/acp-17-2477-2017, 2017. 